University of Rhode Island

DigitalCommons@URI

Open Access Dissertations

1993

\title{
Structural Integration of the Transtheoretical Model of Behavior \\ Change: An Application to Smoking Cessation
}

Linelle Marie Blais

University of Rhode Island

Follow this and additional works at: https://digitalcommons.uri.edu/oa_diss

\section{Recommended Citation}

Blais, Linelle Marie, "Structural Integration of the Transtheoretical Model of Behavior Change: An Application to Smoking Cessation" (1993). Open Access Dissertations. Paper 1081.

https://digitalcommons.uri.edu/oa_diss/1081

This Dissertation is brought to you for free and open access by DigitalCommons@URI. It has been accepted for inclusion in Open Access Dissertations by an authorized administrator of DigitalCommons@URI. For more information, please contact digitalcommons-group@uri.edu. 
STRUCTURAL INTEGRATION OF THE TRANSTHEORETICAL MODEL OF BEHAVIOR CHANGE: AN APPLICATION TO SMOKING CESSATION BY LINELLE MARIE BLAIS

A DISSERTATION SUBMITTED IN PARTIAL FULFILLMENT OF THE REQUIREMENTS FOR THE DEGREE OF DOCTOR OF PHILOSOPHY IN PSYCHOLOGY 


\section{Abstract}

The Transtheoretical Model of behavior change posits that four major components interact in a predictable fashion in affecting change: the stages of Change, the Processes of Change, Decisional Balance, and Self-Efficacy. Yet the various components explicated by the model have yet to be fully structuraliy integrated. To date, virtually all the research on the model has examined the separate components in isolation, as a function of the stages of change, or as predictors of progress across the stages of change. However, the sequencing, direction, and magnitude of those relationships have yet to be examined within a single analytical framework, or as a function of stage movement transitions.

The study has been designed to a) contribute to the development of a more structurally integrated general model of the Transtheoretical Model of behavior change for smoking cessation, b) explicate the relationship among the decisional balance and processes of change model constructs over time and as a function of stage movement transitions, and c) to explore the utility of the derived model for understanding the change process of progressive stage movers for smoking behavior. It is hypothesized that synthesis and assessment of the model components within a single, multidimensional framework together with a consideration of alternative heuristic conceptualizations of this integration, will add to the 
formulation of a more fully integrated Transtheoretical Model.

Analyses are based on data from a smoking cessation study of a population based intervention sample $(\underline{N}=4,144)$. Model integration is achieved through the use of longitudinal panel analysis and dynamic prediction analyses using latent variable structural equation modeling techniques. Such an analytical approach allowed for identification of which constructs represented independent influences on subsequent model constructs over a 6 month time period, which constructs were predictive of smoking habit strength, which relationships differed as a function of the specific stage movement transitions, and whether model relations were consistent across sex. The implications of the derived models for our understanding of behavior change generally, and for tailoring intervention development and program implementation specifically, are considered within the context of a more fully structurally integrated Transtheoretical Model of Change. 


\section{Acknowledgements}

I would like to thank those individuals who have given me support, guidance, and inspiration throughout my graduate career. Much gratitude goes to Joseph S. Rossi, teacher and mentor, for expressing unwavering confidence in my capacity to achieve, providing challenges and opportunities to build the necessary skills to succeed, and modelling a standard of scientific excellence that I will always strive to emulate.

I would also like to thank the faculty and staff of the Cancer Prevention Research Center, especially Joseph Fava and Jim Prochaska, for teaching the value of critical thinking and scientific discourse.

Much love and many thanks go to the friends I have made during my graduate experience, especially to Jen Rose and Jim Arruda whose friendship made graduate school enjoyable and provided an endless source of motivation, to Gabrielle Reed, ageless soul and beachcomber, for her timely, centering gifts from the sea, and to sally Cottrill, Lin Ding, sherri Gold, Sue Rossi, and Janice Tsoh for their continuous and continual encouragement.

I wish to dedicate this dissertation to my parents, Henry and Estelle Blais, who provided the unconditional love and guidance that nurtured a little girl to dream big dreams, and to my husband, stephen Banspach, who with love, sacrifice, and patience, shared in bringing my dream to realization. 
Table of Contents

Page Number

Abstract

ii

Acknowledgements

iv

Table of Contents

$\mathrm{v}$

List of Tables

vi

List of Figures

vii

Introduction

1

Methodology

Subjects

Measures

23

Arialyses

27

Results

Measurement Analyses

Panel Analyses

Prediction Analyses

51

Sex Analyses

Discussion

Appendices

Tables

Figures

Bibliography 
List of Tables

Page Number

Table 1 - Sample Demographics

Table 2 - Maximum Likelihood Loadings for

the 5 Factor Measurement Model

Table 3 - Scale statistics for the 5 Factor

Measurement Model

Table 4 - Scale statistics for the Panel Analyses

Table 5 - Maximum Likelihood Parameter Estimates Total Sample

Table 6. - Comparison of 7 Panel Analyses for Stage Subgroups

Table 7 - Maximum Likelihood Parameter Estimates Precontemplation- >Precontemplation

Table 8 - Maximum Likelihood Parameter Estimates Precontemplation->Contemplation

Table 9 - Maximum Likelihood Parameter Estimates Contemplation- >contemplation

Table 10 - Maximum Likelihood Parameter Estimates Contemplation->Preparation

Table 11 - Maximum Likelihood Parameter Estimates Preparation->Preparation

Table 12 - Comparison of 7 Prediction Model Paths to Habit strength for Stage Subgroups 109

Table 13 - Measurement Model Factor Loadings 
List of Figures

Page Number

Figure 1 - Heuristic Model A

Figure 2 - Heuristic Model B

Figure 3 - Panel Analysis - Total Sample

Figure 4 - Panel Analysis -

Precontemplation->Precontemplation

Figure 5 - Panel Analysis -

Precontemplation-> Contemplation

Figure 6 - Panel Analysis -

Contemplation->Contemplation

Figure 7 - Panel Analysis -

Contemplation->Preparation

Figure 8 - Panel Analysis -

Preparation->Preparation

Figure 9 - Prediction Analysis Model

128

Figure 10 - Panel Analysis - Female

130

Figure 11 - Panel Analysis - Male

132 
Structural Integration of the Transtheoretical Model of Behavior Change: An Application to Smoking Cessation

The risk of cancer and heart disease from cigarette smoking and the passive intake of smoke is impressive. Approximately $30 \%$ of all cancer deaths, $40 \%$ of coronary heart disease (for those under 65 ), and $87 \%$ of lung cancer deaths in the United States could be avoided by the cessation of smoking (USDHHS, 1990). Indeed, one in six deaths is attributable to smoking (CDC, 1991). Despite awareness of such health risks, nearly 50 million Americans continue to smoke and more than 3000 individuals join the ranks of new smokers each day (USDHHS, 1989).

The limited success of traditional health education approaches for smoking cessation attests to the fact that re-acquisition of a smoke free lifestyle requires more than knowledge about the hazards of smoking or an intention to quit. In fact, the majority of smokers are informed about the health risks from smoking and most would like to quit (USDHEW, 1979). Yet, 60\% of smokers who try to quit on their own fail within a short period of time (USDHEW, 1975). Further, $90 \%$ of smokers who do successfully quit, do so without the aid of a formal program (Cohen et al., 1989; Fiore et al., 1988). This is not surprising given that most smokers report resistance to trying 
formalized treatment. Fortunately, most smokers also indicate receptivity to the use of self-help materials (Abrams et al., 1988; Orleans et al., 1988). Unfortunately, most smokers do not take advantage of self-help programs (Orleans et al., 1988; Schmid, Jeffrey, \& Hellerstedt, 1989).

The frustration with recruiting smoker participation in self-help programs results from the naive expectation that action-oriented programs will appeal equally to all individuals regardless of their readiness to change their smoking behavior. In reality, the vast majority of smokers are not ready to quit smoking. Aggregated across studies and populations, only about $15 \%$ of smokers are prepared for action, while the majority, $40 \%$ to $50 \%$, are not thinking about quitting smoking (Abrams, Follick, \& Beiner, 1988; Gottlieb, Galavotti, McCuan, \& McAlister, 1990; Pallonen, Fava, Salonen, \& Prochaska, 1992). Consequently, even the best action oriented self-help programs may result in a low recruitment of smokers, and potentially large numbers of drop out.

Despite this pessimistic review, self-help minimal interventions have demonstrated success rates at least as comparable to formal programs and at lower costs (Cohen, et al., 1989; Glynn, Boyd, \& Gruman 1990; Prochaska, 1992). As such, the last two decades of smoking research do seem to indicate that self-help minimal interventions may provide the appropriate $\mathrm{mix}$ of independent agency and professional 
guidance to affect smoking behavior change. However, for maximum treatment effectiveness, programs must be developed to reach smokers at all stages of readiness to quit smoking. Initiating development of such programs forces the question, what intervention modalities work best for whom and when? Ascertaining an answer to this question must precede questions of program impact if appropriate ameliorative actions are to follow. The first step to deriving such answers is through the application of a well-developed theory. A comprehensive theory provides the means of detecting, observing, and understanding the leverage points in the behavior change process .

One theory that has been particularly effective in a variety of health-related areas is the Transtheoretical Model of behavior change (Prochaska \& Diclemente, 1982, 1983, 1985, 1986; Prochaska, Diclemente, \& Norcross, 1992). The Transtheoretical Model is an eclectic theory, combining the best knowledge of behavior change from competing models into a more complete meta-explanation of smoking behavior. Such an integrative approach to model building has been recommended for the behavior change field generally (Cummings, Becker, \& Mailie, 1980), with the Transtheoretical Model considered a prime example, specifically (Glynn, Boyd, \& Gruman 1990).

Originally developed to synthesize and systematize the field of psychotherapy (McConnaughy, Prochaska, \& Velicer, 
1983; McConnaughy, Diclemente, Prochaska, \& Velicer, 1989; Prochaska, 1979; Prochaska \& DiClemente, 1982), the Transtheoretical Model has been applied successfully across a diversity of problem behaviors including but not restricted to, smoking cessation (DiClemente, Prochaska, Fairhurst, Velicer, Valesquez, \& Rossi, 1991; Prochaska \& DiClemente, 1983; Velicer, Diclemente, Rossi, \& Prochaska, 1990), adolescent cigarette smoking acquisition (Stern, Prochaska, Velicer, \& Elder, 1987), cocaine abuse (Rosenbloom, 1991), alcohol abuse (Snow, Prochaska, \& Rossi, 1992), outpatient alcohol treatment (Diclemente \& Hughes, 1990), dietary fat reduction (Rossi, Rossi, \& Prochaska, 1990), reducing exposure to sunlight (Blais, 1991; Rossi, 1989a, 1989b), mammography screening (Rakowski, et al., 1992), HIV risk reduction (Prochaska, Redding, Harlow, Rossi, \& Velicer, 1991), and adolescent delinquent behavior (Fiore-Lerner, 1990). To date, the most extensive development of the model has been in the area of smoking cessation.

\section{Model Components:}

The Stages of Change. The Transtheoretical Model is a dynamic model. This approach recognizes that people may be at different stages of readiness to change their problem behavior. Rather than a single prediction rule, psychosocial 
variables are viewed as influencing behavior indirectly through the individual's stage of change. Stages are considered qualitatively different, with people at each distinct stage showing different patterns of behavior. Movement through the series of developmental stages indicates progress in modifying the problem behavior. Similar concepts have been discussed by Brownell, Marlatt, Lichtenstein, and Wilson (1986) and Weinstein (1988).

The stages of change concept serves as the core construct of the Transtheoretical Model indicating when change occurs in the natural environment as well as in intervention programs. The stages are defined in terms of both current behavior and future behavioral intention. Retrospective, cross-sectional and longitudinal research indicates that people pass through a series of stages in trying to quit smoking (DiClemente \& Prochaska, 1982; Diclemente et al., 1991; Prochaska \& DiClemente, 1983; Prochaska, DiClemente, Velicer, Ginpil, \& Norcross, 1985; Velicer, Hughes, Fava, Prochaska \& DiClemente, 1992). These five stages are defined as: precontemplation (not intending, to quit within the next 6 months), contemplation (seriously considering quitting in the next 6 months), preparation (seriously considering quitting in the next 30 days and have tried quitting in the past year), action (currently not smoking and have not smoked for a period ranging from 0 to 6 months), and maintenance (currently not 
smoking and have not smoked for a period ranging from 6 months to smoking termination). Termination of smoking as an addictive behavior occurs for most people after 5 years of prolonged abstinence. The six month time frame for the stages of change was chosen based on the assumption that 6 months is about as far into the future that most people plan a specific behavior change.

Transitions between the stages can be viewed as barriers to action (Weinstein, 1988) and to the eventual maintenance of the changed behavior. Indeed, progression through the stages is not linear, since the majority of people relapse and recycle back to an earlier stage. With smoking, usually 3 to 4 serious action attempts are taken before successfully changing smoking behavior. Rather than failing, most relapsers learn from the quit experience and are better prepared for the next quit attempt. Visualizing change as a spiral process rather than as an endlessly revolving circle most accurately conveys the progress gained from past experience (Prochaska, Diclemente, \& Norcross, 1992).

For maximum effectiveness, interventions should be matched to the individual's stage of change. Interventions which are tailored to participants' stage of change have proven more successful than interventions not tailored (Campbell et al., in press; Marcus et al, 1992; Prochaska, DiClemente, Velicer \& Rossi, 1993; Skinner et al., in press). 
Research has also demonstrated that the amount of progress people make in resolving problem behavior is a function of their stage of change. For example, helping people move forward just one stage of change can double the chances that independent action will be taken in the near future (DiClemente, et al., 1991). Further, smoking cessation rates have been found to approximately double across the stages from precontemplation to contemplation to action - in both a study of "healthy" smokers and a study of smokers who are cardiac patients (DiClemente, et al., 1991; Ockene et al., 1992).

The Processes of Change. The Processes of Change are a set of overt and covert strategies and techniques that people utilize in modifying problem behavior. These processes indicate how people change attitudes, intentions and behaviors. In the original retrospective work with smoking cessation, a common set of 10 change processes were identified for both selfchangers and therapy changers (DiClemente \& Prochaska, 1982). These processes were based on a comparative analysis of leading systems of psychotherapy including psychoanalysis, behaviorism, the experiential methods of the cognitive therapies, and existentialism (Prochaska, 1979). For both change groups, the processes of change were found to vary in importance as a function of stage. Additional studies 
confirmed that people in different stages of change utilize different processes of change (Prochaska, et al., 1991). For example, the consciousness raising process is a cognitive strategy that increases information about the pros and cons of a particular problem. It is used to progress from the precontemplation stage to the contemplation stage. Other processes such as self-reevaluation predict successful change from contemplation to action.

Mismatching or over-utilization of certain processes has implications for progress through the stages of change. Misapplication of the processes is predictive of relapse or lack of. movement. For example, longitudinal research indicates that individuals who rely on consciousness raising and self-reevaluation when in the action stage are mismatching processes to stage and are prone to relapse. Conversely, contemplators who over-utilize the process of consciousness raising ("chronic contemplators") obsessively gather information at the expense of making a commitment to change and moving on to action (Prochaska, et al., 1985).

As an intervention strategy, effective treatment requires the differential employment of selected change processes at strategically critical times in the course of change (Prochaska, et al., 1992). Intervention programs which design action-maintenance oriented programs but that include individuals in the precontemplation or contemplation stages of 
change tend to demonstrate little to no effect or even negative effects. For example, an intensive actionmaintenance oriented treatment program for cardiac patients was highly successful for smokers who were ready for action (94\% abstinent), but failed for smokers who were precontemplators $(0 \%$ abstinent) and contemplators (35\% abstinent) (Ockene, et al., 1992).

Processes X Stage. Each of the processes of change follows a general pattern of climbing from precontemplation to contemplation, peaking at a particular stage of change, and then descending to precontemplation or contemplation levels or to somewhat higher levels if the process is used as a relapse strategy (Prochaska, et al., 1991). This ascending-descending profile pattern has been dubbed "Mt. Change" - a useful metaphor for introducing the behavior change process.

Structural analyses of the processes of change indicate that the processes can be divided into two higher order levels: experiential processes and behavioral processes (Prochaska, Velicer, DiClemente, \& Fava, 1988). This hierarchical structure has been replicated across smoking, exercise, weight control, alcohol use, psychological distress, HIV risk reduction, dietary fat reduction, cocaine use, and heroin use (Rossi, 1992). In general, experiential processes are more heavily utilized in the earlier stages of change 
while the behavioral processes are more heavily utilized in the action and maintenance stages of change. Precontemplators use both the experiential and behavioral processes infrequently (Prochaska, et al., 1985; Prochaska, et al., 1991).

Decisional Balance. Decisional Balance is based on the theoretical model of decision making developed by Janis and Mann (1977). This construct was initially applied to assess the pros and cons of smoking as they relate to the stages of change. The pros represent the positive aspects of smoking behavior. The cons represent the negative aspects of smoking behavior. Part of the decision to move to action is based on the relative weight given to the pros and cons of changing behavior. The pros and cons have been very successful in predicting action for smoking (Velicer et al., 1985), weight control (O'Connell \& Velicer, 1988), psychological distress (Penney, 1988), HIV risk reduction (Prochaska, et al., 1991), radon exposure (Rossi, 1990), and sunscreen use (Rossi \& Blais, 1991).

Decisional Balance $X$ Stage. Longitudinal studies on the pros and cons of smoking across the stages of change for smoking cessation follow a general pattern of the pros of smoking decreasing linearly as a function of stage and the cons 
increasing linearly as a function of stage (Velicer, et al., 1985; Prochaska, et al., 1991). At precontemplation, the positive aspects of smoking are much higher than the negative aspects of smoking behavior. The negative aspects of smoking are about equal or "balance" with the positive aspects of smoking and then begin to outweigh the positive aspects of smoking early in the contemplation stage. Thus, decisional balance is an excellent indicator of an individual's decision to move out of the precontemplation stage. In the preparation stage, the cons of smoking clearly outweigh the pros, remaining higher through the Action stage, although both the pros and cons then begin to decline in importance. During the maintenance stage, the pros and cons continue to decrease as the problem cessation behavior becomes a less salient issue. To date, this decisional balance pattern across the stages of change has been found to replicate across 12 problem behaviors (Prochaska, et al., in press).

The decisional balance pattern across the stages of change for the 12 problem behaviors has led to the discovery of two principles for progressing from the precontemplation to action stage of change. A strong principle of progress states that progress from precontemplation to action is a function of approximately 1 standard deviation increase in the pros of a health behavior change. In this study, the corollary would be 1 standard deviation increase in the cons of smoking. A weak 
principle of progress states that progress from precontemplation to action is a function of approximately onehalf standard deviation decrease in the cons of a health behavior change (pros of smoking).

Self-Efficacy. Self-efficacy is another important construct of the Transtheoretical Model. Based on the work of Bandura (1977, 1982), the concept of self-efficacy reflects the degree of confidence and temptation experienced across a variety of problem situations. The situational component of the selfefficacy construct also relates to the coping models of relapse and maintenance pioneered by Shiffman (Shiffman, 1982, 1986; Velicer, DiClemente, Rossi, \& Prochaska, 1990). The predictive power of self-efficacy to future behavior has been demonstrated in several studies (Coelho, 1984; Condiotte \& Lichtenstein, 1981; DiClemente 1981; DiClemente, Prochaska, \& Gibertini, 1985; McIntyre, Lichtenstein, Mermelstein, 1983).

Self-Efficacy X Stage. Research into the stages of change for smoking cessation (Prochaska, et al., 1985) indicate that self-efficacy evaluations are quite reliable predictors of movement into action and maintenance. Longitudinal studies of self-efficacy and smoking reveal that confidence increases linearly with stage while temptation levels decrease linearly (Prochaska, et al., 1991). Confidence and temptation levels 
converge and remain roughly equal throughout the action stage. Not until individuals are moving into the maintenance stage of change does confidence become greater than temptations to smoke. Confidence levels reach their peak about 18 months after smoking cessation while temptation levels continue to decline for up to three to five years after cessation. As such, measures of confidence and temptation are good indicators of the likelihood of relapse (DiClemente, 1981, 1986; DiClemente, Prochaska, \& Gibertini, 1985; Rossi et al., 1989). However, self-efficacy does not emerge as relevant for earlier.stage movement. Predictions of movement out of the precontemplation and contemplation stages seem more related to the pros and cons of the decisional balance construct and the experiential processes of change.

Self-Efficacy $X$ Processes of Change $X$ Stage. A microanalysis of the relationship between self-efficacy, the stages of change, and change process activity suggest an interesting link among the constructs. Efficacy evaluations appear to modulate or to be modulated by process activity differentially by stage. Higher efficacy scores among precontemplation and contemplation stage subjects correlate with greater change process activity. However, in action and particularly in maintenance, subjects' higher smoking abstinence self-efficacy correlate with decreased change process activity (DiClemente 
et al., 1985). Thus, while self-efficacy appears to have a more critical role in successful behavior change during the later stages of change, pre-action self-efficacy evaluations may contribute to the relative use of the processes of change. Baer, Holt, \& Lichtenstein (1986) posit that part of the predictive power of self-efficacy may result from the relation that exists with current smoking behavior. Indeed, the longitudinal pattern of change for self-efficacy is identical to that hypothesized for Habit Strength - a composite outcome measure including one's stage of change, temptation to smoke, and the number of cigarettes smoked (Prochaska, et al., 1991). Temptation is defined as the degree of temptation experienced across the same challenging situations comprising the selfefficacy measure.

In this current study, Habit Strength (Velicer et al., 1992) will be used as the behavioral outcome measure. As such, self-efficacy will not be assessed as a separate construct due to its high correlation with this outcome variable. Additionally, this present study sample did not include a measure of self-efficacy due to high correlation with the temptation construct. Given such methodological constraints with the self-efficacy measure, self-efficacy as a construct in the Transtheoretical Model was not looked at within the scope of the present investigation. Rather, the primary goal was to understand the relations among those 
variables which pose the most likelihood of contributing to our understanding of behavior change in a reliable and interpretable manner.

Overview of the present research.

While the Transtheoretical Model is dynamic and eclectic, the various components explicated by the model have yet to be integrated into their full synergistic potential. Virtually all the research on the Transtheoretical Model has examined particular components of the model in isolation or as a function of the stages of change. None has attempted to examine all model components relationships to one another within a single analysis as a function of stage transitions. The theoretical linkages among the stages, processes of change, decisional balance, and self-efficacy constructs are consistent with the extensive research to date on the Transtheoretical Model and that of the competing models it subsumes. Yet until the model variables are examined simultaneously, it is difficult to determine whether each construct represents an independent influence on the outcomes, whether certain constructs mediate others in effecting change, and whether relationships among the model constructs differ as a function of various stage transitions. This study attempted to initiate this process by looking at the relationship among 
three of the four Model constructs - the experiential and behavioral processes of change, the pros and cons of decisional balance, and stage of change (stage transitions).

The study has been designed to a) contribute to the development of a more fully structurally integrated general structural equation model of the Transtheoretical Model of behavior change for smoking cessation among the processes of change and the decisional balance constructs, b) explicate the relationship between these posited model constructs over time ( 6 months) and as a function of stage movement transitions, and c) to explore the utility of the more fully structurally integrated model for understanding the change process of progressive stage movers. It is hypothesized that synthesis and assessment of these model components within a single, multidimensional framework together with a consideration of alternative heuristic conceptualizations of this integration, will add to the formulation of a general model for smoking cessation that is of both explanatory and predictive utility. The analytical approach of this study is quasiexploratory. First, a proposed measurement model is tested and examined using structural equation techniques for assessment of model fit to the data. Next, various heuristic conceptualizations of model integration are considered through examination of every relevant category of stage movement and non-movement from precontemplation to action that has 
sufficient numbers of subjects to permit the analyses.(i.e., precontemplators who move to contemplation, contemplators who move to preparation, preparation people who moved to action, precontemplators who remained in precontemplation, contemplators who remained in contemplation, preparation people who remained in preparation). As such, movement from Action to Maintenance, was not investigated as so few subjects represent this movement at any given time. Regression or relapse from later stages is also not assessed as the study intent is to examine relationships among variables for progressive stage movers only.

By focusing only on succéssful stage transitions relative to non-progressive stage movement categories, we purposely choose not to explore the natural movement history of all individuals representing the various stages of change. Rather, progressive movers within the stages serve as models of successful change processes. By analyzing models separately by stage movement transitions, we recognize stage as the core construct of the Transtheoretical Model critical to understanding the change process and for developing more effective intervention strategies. Analyses which address issues and relations of all the stages at once within a single analytical framework must await the development of appropriate methodological technology. 
The structural integration process involves three phases - measurement analysis, longitudinal path analysis, and dynamic prediction analysis. The measurement analyses use cross-sectional data to examine the adequacy of the proposed Transtheoretical Model. The path analyses and prediction analyses use longitudinal data to examine the predictive relationships among the pros and cons of decisional balance and the experiential and behavioral processes of change model constructs, and to examine the relationship of these model constructs to a behavioral outcome, Habit strength, respectively. The longitudinal design allows an assessment of the direction of causal influence by prospectively examining the ability of various constructs to predict subsequent changes in other constructs - the first examination of these relations over a 6 month period. The result of these analyses will be the development of a more fully and structurally integrated Transtheoretical Model for smoking behavior change, and a clearer, more utilitarian understanding of the behavior change process for smoking cessation.

\section{Study Caveats:}

The intent of this study was not to "test" specific conceptualizations of a more fully prescribed structural model by either acceptance or rejection based on model fit indices. Indeed, Cliff (1983) cautions that in the use of structural 
equation modeling techniques, there are an infinite number of models that may fit the data well. However not all models are equally meaningful or theoretically driven. Rather, structural equation modeling is a powerful tool for revealing the plausibility of a proposed causal model, the nature of its posited relationships, and the degree of its explanatory power. As a correlational technique, it cannot claim to confirm the Transtheoretical Model or ascertain causal relationships. Yet given that caveat, the Transtheoretical Model does specify more general types of relations within the context of the more fully structurally integrated model that should or should not be observed among the various variables and constructs. For example, the Transtheoretical Model hypothesizes that increased use of the experiential processes of change should result in an increase in the cons from the decisional balance scale which in turn should result in a decrease in smoking behavior. Thus, it is possible to observe the presence or absence of higher order relations among constructs that violate or weaken some of the theoretical premises posited by the Transtheoretical Model. However, more microlevel relations (i.e., the specific Processes of Change utilized as a function of stage) are beyond the scope of this present investigation.

As such, the intent of this study is to more clearly explicate the relationships among the decisional balance and 
processes of change model constructs so as to better understand the influence and sequence of model components in the behavior change process. The results of such an investigation serve to strengthen or weaken support for the relations specified by alternative heuristic conceptualizations for the integration of the Transtheoretical Model of Behavior Change.

One last delimiting of the study intent involves examination of traditional demographic variables. While interesting, such variables will not be examined as part of the model proposed for smoking cessation in the current study. Rather; for purposes of generalizability, the model relationships were examined for consistency as a function of sex - male and female. This decision was based on the fact that demographic variables have proven of little utility in predicting subsequent behavior change. For example, the Processes of Change have been found to be better predictors of progress across the stages of change than were a set of 17 predictors variables including demographics, smoking history and severity, health history, withdrawal symptoms, and reasons for smoking (Prochaska, et al., 1985; Wilcox, et al., 1985). Indeed, use of the experiential and behavioral processes accounted for 8 times as much variance in smoking as a similar set of demographic variables (Fitzgerald, Rossi, \& Prochaska, 1989). The ten processes also outperformed 6 demographic 
variables in predicting action for exercise (Marcus, et al., 1992). Further, while there may exist demographic differences among subjects on variables posited by the Transtheoretical Model, research to date has yet to evidence significant changes in the structure of the relationships among the Model constructs based on demographics (Bellis, Rossi, \& Prochaska, 1990). Such findings are encouraging given the dynamic nature of the variables posed in the Transtheoretical Model. Unlike static demographics or personality traits, such variables are open to change. Understanding the correlations among such variables and their function as predictors of change will allow for the identification of critical leverage points that can guide health promotion and prevention efforts. Understanding any differences in the relations among constructs due to sex will allow for further refinement of the Model .

Thus, this study presents an attempt at structurally integrating multiple behavior change constructs from diverse theories within the posited framework of the Transtheoretical Model of behavior change. It represents an attempt at building a more structurally integrated Transtheoretical Model through a systematic and rigorous series of structural modeling analyses. By synthesizing and assessing the model components within a single, multidimensional framework for progressive and non-progressive stage movers, and by 
considering alternative heuristic conceptualizations of model integration, it is hypothesized that a clearer explication of the behavior change process in totality will emerge, resulting in a more comprehensive and targeted approach to developing, implementing, and evaluating intervention programs for individuals across all stages of change.

METHODOLOGY AND PROCEDURES:

SUBJECTS -

Subjects are participant's from a population based smoking cessation intervention sample from Rhode Island ( $\underline{N}=4,144$; Velicer, et al., 1993). Subjects were recruited through a random digit dialing ( $R D D$ ) survey among a population of 338,411 possible households in the state of Rhode Island for a longitudinal study of smoking cessation interventions. Out of a population of 615,167 adults between the ages of 18 and 75 years of age, 14,266 (84.9\%) eligible subjects were contacted. More than 35\% of these interviews $(N=4,296)$ were conducted with cigarette smokers. Names and addresses for follow-up contacts at 6 months were obtained from 96.5\% of interviewed smokers, leaving a total sample of 4,144 smokers.

Sample characteristics of this sample are as follows: the mean age of the sample is 40.7 years; $55.7 \%$ of subjects are 
female; $95.7 \%$ are White; median education is 12 years; $70.7 \%$ are employed; median income is $\$ 30,000$ to $\$ 40,000 ; 53.5 \%$ are married. Participants smoke an average of 20.6 cigarettes per day, having started smoking on average at the age of 16.4. Stage distributions at baseline indicated that $42.1 \%$ of subjects were in precontemplation, $40.3 \%$ in contemplation, and 17.6\% in preparation. The stage distribution at 6 months indicated that $43.8 \%$ of subjects were in precontemplation, $34.8 \%$ in contemplation, $13.3 \%$ in preparation, and $8.1 \%$ in action. Sample demographics are detailed in Table 1.

MEASURES -

Smoking Habit strength. Habit strength is a composite of variables comprised of the number of cigarettes smoked per day and the Temptation to Smoke scale. The Temptations to Smoke scale assesses the level of subjects' temptation to smoke across the 17 challenging situations. It is measured on a 5point Likert scale $(1=$ not at all tempted, and $5=$ extremely tempted). Habit strength has included the stage of change variable in its composition (Velicer, Rossi, Prochaska, \& DiClemente, 1992). However, in this study, analyses are conducted separately for each movement subgroup across the stages of change from precontemplation to action. As such, the stage of change construct is not included in the set of 
composite variables for smoking Habit strength.

The choice of Habit Strength as an outcome measure was based on considerations of statistical power and meaningfulness (Velicer, Prochaska, Rossi, \& Snow, 1992). As a continuous measure, Habit strength is more sensitive to changes in behavior and is a more meaningful outcome for individuals making intermediate smoking changes across all stages in the change process (Velicer, Rossi, Prochaska, \& Diclemente, 1992). For example, traditional dichotomous measures such as smoking/not smoking are inadequate to assess movement from precontemplation to contemplation as such a change does not involve a quit attempt or necessarily, a reduction in cigarettes smoked per day. Temptation levels, on the other hand, have been found to decrease across the stages of change, However, research to date suggests that level of temptation may be a more important predictor of the relative use of processes of change during the precontemplation and contemplation stages, but a more important predictor of movement into action and maintenance than from precontemplation to contemplation (DiClemente et al., 1985). Together, assessment of change in the number of cigarettes smoked and temptation level experienced, creates a continuous outcome measure that is more appropriate across all stages of change. 
Stage of Change Scale. This measure assesses subjects' readiness to change their problem behavior. Developed for smoking cessation (DiClemente, et al., 1991; Prochaska and Diclemente, 1983), the stages of change are: precontemplation (not thinking about quitting smoking in the next six months); contemplation (seriously thinking about quitting smoking in the next six months); preparation (intending to quit smoking in the next 30 days and have tried quitting within the past year); action (not smoking and have quit within the last 6 months); and maintenance (have not smoked for more than 6 months). In this study, subjects who exhibit movement from an earlier to a later stage of change will form stage subgroups (e.g:; precontemplators who move to contemplation, contemplators who move to preparation, preparation people who move to action). Subjects who do not exhibit movement to a later stage but remain in the same stage over the 6 month time period will form non-progressive stage subgroups (e.g., precontemplators who remain in precontemplation, contemplators who remain in contemplation, preparation people who remain in preparation) .

Background Measures. Demographics, smoking history, weight history, health history, and other traditional summary smoking measures were asked at baseline. Such data are available for analyses as needed and can be found in Table 1 . 


\section{Process Measures:}

Decisional Balance Scale. This measure is a 20 item questionnaire that measures the Pros (10 items) and the Cons (10 items) of Smoking (Velicer, DiClemente, Prochaska, \& Brandenberg, 1985). A short form of this measure has also been developed and was used in this study. It consists of 3 Pros items and 3 Cons items (Fava, Rossi, Velicer, \& Prochaska, 1991). Subjects rate how important each item is in making a decision to smoke or not to smoke using a 5 point Likert scale $(1=$ not at all important; $5=$ extremely important). The pros and cons subscales were used as separate constructs in the structural models.

Processes of Change Questionnaire. This measure is a 40 item questionnaire assessing 10 processes of change, 5 experiential processes and 5 behavioral processes. Four items represent each of the ten processes. A short form of this measure was used in this study and consists of 20 items. The experiential and behavioral higher order factors were assessed separately in the structural equation models. Each was measured by 5 parcels of 2 items per parcel (Fava, et al., 1991; Prochaska et al., 1988). Unlike the pros and cons constructs, scale scores rather than items are used to define the experiential and behavioral processes constructs. On a five point Likerttype scale, subjects are asked to rate how frequently they 
employed each item in the past month $(I=$ not at all; $5=$ repeatedly).

The Stage of Change Scale, Temptations to Smoke Scale and the process measures have high reliability, internal validity, discriminative and predictive validity (Prochaska, Velicer, DiClemente, \& Fava, 1988; Velicer, et al., 1990). Internal consistency for the process measures have been found to range from .67 to .96 (median $=.83$ ).

\section{Analyses}

Three distinct analytical phases were conducted in this study: 1) measurement model analyses, 2) longitudinal two-wave panel analyses, and 3) longitudinal prediction (dynamic) analyses.

These three analytical steps represent a rigorous series of causality-oriented assessments of the Transtheoretical Model of behavior change. In each instance, structural equation modeling techniques were used to evaluate model relations and to assess model fit to the data.

For the measurement analyses specifically, structural equation modeling allows for an evaluation of the contribution of multiple manifest (observed) measures to the measurement of the latent (unobserved) constructs hypothesized by the Transtheoretical Model of behavior change. Previous 
applications of confirmatory structural equation modeling to measures based on the Transtheoretical Model have proven very successful (Blais, 1991; Prochaska, Diclemente, Velicer, \& Fava, 1988; Rossi, 1992; Velicer et al., 1990). For the panel and dynamic analyses, latent structural equation modeling permits an assessment and evaluation of the relationships among the latent (unobserved) model constructs, the consistency of these relations to the sequence proposed by alternative heuristic model conceptualizations, and the consistency of these patterns of relations with more general types of relations that should be observed among the constructs as proposed by the. Transtheoretical Model of Behavior Change. For the panel and prediction analytical approaches, analyses are also conducted for each stage subgrouping from precontemplation to action representing movement and non-movement along the developmental continuum toward smoking cessation behavior change. Only progressive movers and non-progressive movers within each stage transition group are investigated to facilitate understanding of a successful behavior change process. Subjects who relapse are not considered in this study.

Evaluation of the models across the three analytical phases of this study requires an assessment of the model's overall fit to the data. Because no overall index has been agreed upon as the preferred measure of fit, Marsh, Balla, and 
McDonald (1988) recommend that several different indices of fit be computed and compared to determine goodness of fit. Four different indices of fit were used to assess the measurement model. The maximum likelihood (ML) $\chi^{2}$ statistic is an absolute measure of fit (without reference to the null model). As the $\chi^{2}$ statistics are highly dependent on sample size and sensitive to distributional violations, they will not be used as a sole source of model evaluation but as a basis for comparison with other fit indices. The Root Mean square Residual (RMR) is another absolute index and is a measure of non-fit of a model (Jöreskog \& Sörbom, 1989). The TuckerLewis non-normed fit index (TLI: Tucker \& Lewis, 1973), and the comparative fit index (CFI; Bentler, 1990) are all indices of relative fit as compared to the null model.

Higher values indicate better fit for the TLI, and the CFI with '1.0' being a perfect fit and ' $O$ ' indicating a lack of fit. Values below .90 are generally considered indicative of the need for further improvement. For the $\chi^{2}$ and the RMR indices, lower values indicate better fit. For RMR, values of .05 or less are considered an acceptable measure of non-fit. 
Results

I. Measurement Model Analyses

Confirmatory factor analysis using structural equation modeling (Bentler, 1989; Jöreskog \& Sörbom, 1989) was conducted on baseline data from the total smoking sample $(\underline{N}=$ 4,144). Cross-sectional data using covariance matrices were employed to determine if a 5 factor correlated measurement model represented an adequate organizing schema for the observed measures. This model proposes the existence of 5 related latent constructs for the Transtheoretical Model of behavior change and a behavioral outcome variable, Habit Strength. Support for this model would suggest that smokers differentiate between the pros and cons of smoking, the experiential and behavioral processes of change, and the Habit Strength construct. While Habit strength is not a component of the Transtheoretical Model, it is included in this model as an outcome variable whose measurement properties must be assessed if it is to be used in subsequent analyses.

\section{Five Factor Correlated Measurement Model}

The 5 factor correlated measurement model using baseline data provided an adequate fit to the data, $\chi^{2}(125)=1820.137$, $\mathrm{TFI}=.884, \mathrm{CFI}=.905, \mathrm{RMR}=.036$. The maximum likelihood 
estimates were obtained for the factor loadings of the 16 items representing the pros and cons, and the experiential and behavioral processes scales (Table 2). The Pearson correlation coefficients among the 4 model construct scales are shown in Table 3 . The factor loadings had a mean of .608 with a range of .354 to .934. All factor loadings were statistically significant $(P<.001)$.

The coefficient alphas (Cronbach, 1951) for the pros, cons, experiential, behavioral processes, and habit strength scales were $.61, .59, .77, .67$, and .50 , respectively. Given the number of indicators per scale, the magnitude of the alphas at baseline is adequate. Similarly, considering the homogeneity of the sample (primarily smokers in precontemplation and contemplation), the factor loadings are acceptable. Further investigation of the measurement model at 6 months using a more heterogeneous sample that included smokers who had moved into the action stage, indicated an improvement in the alphas for the pros, cons, experiential and behavioral scales $(.69, .72, .77, .69, .53$, respectively), and a slight increase in the factor loadings (mean $=.622)$ (Table 2).

For the habit strength scale, the coefficient alpha (Cronbach, 1951) was low, .50 at baseline and .53 at 6 months. The factor loadings for habit strength were low for the cigarettes per day manifest variable (.354) and very high for 
the temptation variable (.934) defining the construct. Such a pattern for the two item measure suggested the potential for problems in subsequent model testing with this construct due to the near singularity of the temptation item to the construct variance as a whole.

The absolute value of the factor correlations ranged from .000 to .869 at baseline, and ranged from .044 to .852 at 6 months for the 5 factor correlated measurement model. The correlation parameter between the cons and the experiential factor was fairly high (.869) warranting further exploration to determine whether the relation was an artifact of the measurement model or whether the relationship was a stable characteristic of the sample data.

Several exploratory analyses were conducted to investigate the correlation between the cons and the experiential factor, only some of which are discussed in this paper. Analyses to determine the possibility of a measurement problem involved removal of specific items with loadings that were most highly correlated between the two factors or indicated a low factor loading (i.e.,; Social Liberation and Self-Re-evaluation were removed from the experiential factor). However, such investigations did not substantially affect the correlation between the Cons and the Experiential Processes, and further, the removal of manifest variables did not serve to significantly increase the alpha of the constructs. 
Consequently, no items were deleted from the measurement model. While removal of the cons construct or the Experiential construct was an alternative and was assessed, the decision to remove a major construct of the Transtheoretical Model at this phase would have limited our exploration of the more fully integrated Model and would not have served to explain the source of the correlation between the two constructs.

Lastly, to determine whether the correlation between the cons and experiential construct was resulting from the data, the measurement model was conducted for the sample using data collected at the 6 month follow-up period. The correlation among the two constructs was slightly lower but still high (.852) supporting the contention that the correlation evidenced was a function of the data rather than an artifact of the measurement model. As such, the 5 factor correlated model was considered a reasonable and theoretically relevant organizing schema for the observed measures.

Scale statistics, including means and standard deviations, were computed for the 5 factor model (Table 3). No significant problems with skewness (baseline range $=.15$ to $.53 ; 6$ month range $=.15$ to 1.18 ) or kurtosis (baseline range $=-.00$ to $.75 ; 6$ month range $=-.04$ to 3.61 ) were indicated. 
II. Longitudinal Panel Analyses

The temporal relationships between the four model constructs, the pros of smoking, the cons of smoking, the experiential processes, and the behavioral processes, were evaluated over time ( 6 months) by means of a two-wave panel analysis using covariance matrices for the total sample and for each staging movement and non-movement subgroup represented from the precontemplation stage to the action stage in which there were adequate numbers of subjects available to permit analysis. In these analyses, participants attitudes and behavior at time 1 were compared with their attitudes and behavior at time 2 ( 6 months later). The panel design was adopted to better understand the nature of observed relationships as a function of a smoker's movement across the stages of change, to better determine which of two heuristic models for the sequencing of the behavior change process was most plausible, and to help assess the consistency of the observed relationships with general relationships posited by the Transtheoretical Model of Behavior Change.

\section{Model A:}

The first conceptualization (A) for the integration of the Transtheoretical Model posits that people pass through a 
series of Stages during which the Processes of Change are utilized in changing problem behavior. The intervening constructs, the pros and Cons of changing behavior, mediate the relationship between the processes and behavior (Figure 1). This mediator variable can be used to monitor intervention effectiveness, assess progress in resolving problem behavior, and isolate points of difficulty in the change process that need special attention to prevent relapse.

Essential to this model conceptualization is the concept of the processes as the independent variables or the initiators of subsequent cognitions and behavior: The causal implications for smoking behavior would be as follows: Use of cognitive and emotional strategies and techniques directly determine perceptions of the positive and negative aspects of smoking including perceptions of the barriers and facilitators to changing smoking behavior. Depending on intention to change or stage of change for smoking, use of the processes will vary in amount and kind. This variability subsequently influences the weighting of the Pros and Cons of smoking which directly influence Habit strength. By influencing decision making, the Processes of Change indirectly determine eventual Habit Strength. Under such a model conceptualization, interventions would be most successful if they attempt to manipulate both the amount of process use and the types of processes used. 
Previous research supportive of this model conceptualization has been done by Prochaska et al., 1985 and Velicer, et al, 1992. In the former study, which investigated 14 different measures as predictors of change in smoking status for self-change efforts in smoking cessation. Of the six significant discriminant functions, change processes, self-efficacy, and decisional balance variables were found the most efficacious variables, suggesting the potential that the processes may serve as independent variables predictive of behavior. In the latter study, the directional relationship between the pros and cons of smoking behavior and a measure of habit strength was conducted in a 5 wave panel design. Results suggested that behavior (habit strength) influenced subsequent attitudes rather than attitudes (pros and cons) influencing behavior. In as much as experiential and cognitive processes are considered "behaviors", this study would infer that processes might well precede the pros and cons of decisional balance.

\section{Model B:}

The second alternative conceptualization for the integration of the Transtheoretical Model (B) posits a causal chain in which people pass through a series of stages in which the Decisional Balance construct is the independent variable and the Processes of Change construct is the intervening 
variable (Figure 2). In this model, the Processes of Change can be used to monitor intervention effectiveness, assess progress in resolving problem behavior, and isolate points of difficulty in the change process that need special attention to prevent relapse.

The causal implications of the model are as follows: The weighting and prioritizing of the various pros and cons of smoking, barriers and facilitators which formulate smoking decisions, directly influences the amount and kinds of processes or emotional and cognitive strategies and techniques utilized to subsequently change smoking behavior. Depending on intention to change or stage of change for smoking, the weighting of the pros and cons will vary. This variability subsequently influences the amount and selection of strategies and techniques that will be used to change smoking Habit strength. By influencing the processes of change, the pros and cons of decision making indirectly determine eventual smoking Habit Strength. Given such a model conceptualization, maximum intervention effectiveness would be obtained by manipulating the balance of the pros and cons of decision making to the degree that is necessary to move individuals to the next stage of change.

In support of this model, research on the pros and cons has been done by (Prochaska, et al., in press). This study demonstrated that the predictive power of the pros and cons of 
decisional balance in moving people from precontemplation to action across twelve problem behaviors, including smoking, could be consistently expressed with 2 function statements called strong and weak principles of progress which specified that approximately 1 standard deviation increase in the pros of a health behavior, and $1 / 2$ standard deviation in the cons of a health behavior were necessary to progress from the precontemplation to action stage of change. However, the data used in this study are cross-sectional and as such, changes in the pros and cons could easily follow behavior change as lead it. Yet, the large changes in stage associated with substantial changes in the pros and cons support a strong role of the pros and cons in effecting subsequent behavior.

\section{General Model Relationships}

According to the Transtheoretical Model of behavior change, several general types of relationships between constructs should be observed within the context of the more fully integrated model. These relationships include the following general hypotheses:

1. Increased use of the experiential processes of change, decreased use of the pros and increased use of the cons of smoking should be most influential for movement out of precontemplation and contemplation. 
2. Increased use of the experiential processes of change should be more influential in the early stages of change (precontemplation to contemplation) than the increased use of the behavioral processes of change which are more utilized in the later stages of change (preparation to maintenance).

3. Evaluation of the pros and cons of decisional balance should be more influential in the early stages of change consistent with their status as predictors of movement from precontemplation and contemplation to the action stage of change, after which they decline in saliency.

4. The behavioral processes of change should be negatively related to smoking outcome (habit strength).

5. The pros of smoking should be positively related to habit strength.

6. The cons of smoking should be negatively related to habit strength.

The panel analyses help address the following questions: Which model conceptualization (A or B) seems most plausible given the observed predictive relationships among the factors 
to each other over time (Do attitudes influence subsequent behavior, or does behavior influence subsequent attitudes?)? What is the direction and magnitude of influence of construct relations? Do the observed relationships between variables conform to the theoretical assumptions posited by the Transtheoretical Model? Do the observed relationships vary as a function of one's stage transition subgroup? And finally, given these findings, what is the practical relevance of the observed patterns of relationships to our understanding of the smoking cessation process, and for the design, implementation, and evaluation of effective smoking interventions for individuals across all stages of change?

In figures 3-8 of the two wave panel designs, the first four latent variables (first column) represent the 4 model constructs at baseline (pros, cons, experiential and behavioral processes). The second column represents the same constructs at time 2 ( 6 months). The path between the same variable across time indicates the degree of stability of that variable over time. Although not shown in the figures, correlated error was present and was represented by significant paths between manifest variables measured at both time points. The diagonal paths between the two columns of latent variables are of most interest. These paths measure the extent to which a change in the constructs at baseline predict a change in the constructs at 6 months. Larger path 
coefficients indicate greater influence, with the sign of the coefficient indicating the direction of that influence.

\section{Panel Analysis - Total Sample}

Panel analysis was conducted for the total sample of smokers at baseline who had complete data at 6 month follow-up $(N=3,465)$. Significant path coefficients from baseline to 6 months are indicated in Figure 3. The paths between the factors to themselves were high for all but the cons factor indicating a degree of stability over time for three of the four factors $(.71, .32, .67, .60)$. The largest diagonal path was from the experiential processes of change at time 1 to the cons of smoking at time 2 (.66), followed by a path from experiential process to the pros of smoking (.38). Thus, as the experiential processes increase, the cons of smoking increase, and to a much lesser extent, as the experiential processes decrease, the pros of smoking decrease. Other significant paths of lesser influence indicate that as the behavioral processes increase the pros decrease, and as the behavioral processes decrease, the cons of smoking increase, and as the cons of smoking increase the pros of smoking decrease (Table 4).

Thus, the overall model suggests that the experiential processes are of most import to subsequent smoking attitudes (pros and cons), followed by the influence of the behavioral 
processes and the cons of smoking at time 1 again on attitudes at time 2. Of most import, the pros and cons did not influence subsequent process use. While this total sample did not take into consideration the smokers' stages of change, $82 \%$ of the total sample is in the precontemplation or contemplation stage of change at baseline, and $79 \%$ at 6 months. Such a distribution of predominantly early staged smokers in this subsample is probably influencing the total sample results.

The factor correlations and parameter estimates for the model at baseline and 6 months are shown in Table 5. The model fit to the data was good $\left(\chi^{2}(420)=2603.485\right.$, TLI $=$ $.932, \mathrm{CFI}=.942, \mathrm{RMR}=.029)$. A moderate percent of variance was accounted for in all four factors (pros, cons, experiential, behavioral) at time 2 by the factors at baseline $\left(R^{2}=.52, .56,55, .44\right.$, respectively). Of specific note is the high correlation between the experiential and cons factors at baseline (.878) which decreases substantially at the 6 month time period (.697). The large path coefficient (.66) from the experiential processes to the cons factor at 6 months helps to explain the size of the observed correlation between the factors when examined cross-sectionally at baseline, and underscores the importance of employing a prediction framework when trying to understand the relationships among variables. 


\section{Panel Analyses - Stage Transitions}

Panel analyses were conducted for stage of change subgroups exhibiting movement from an earlier stage to a later stage in the developmental continuum, and for those subgroups which remained in the same stage of change at the follow-up period. The subgroups examined and their respective sample sizes are shown in Table 6. Adoption of such a staged analytical approach permitted a more specific assessment of the process of behavior change and the relations among constructs specific to each stage subgrouping of change. Such a model examination approach promised the most utility and remains theoretically consistent with the philosophy of segmenting populations in order to better target or match intervention strategies.

\section{Precontemplation -> Precontemplation}

In this first of the non-progressive subgroups $(\underline{\mathrm{N}}=$ 1,031), the only significant paths indicated in the model were three high stability coefficients from the pros, cons, and experiential factors to themselves at time $2(.77, .92, .87$, respectively). No diagonal paths reached significance (Figure 4). This pattern suggests that little activity is occurring in this precontemplator subgroup, with the pros, experiential and behavioral processes remaining stable over time (Table 4), but with no significant additional influence on attitudes and 
behavior over the 6 month period.

The factor correlations and structural parameters of the model are presented in Table 7. The model fit to the data was good, $\chi^{2}(420)=1093.034$, TLI $=.916, \mathrm{CFI}=.928, \mathrm{RMR}=.035$. A moderate percent of variance was accounted for in all four factors (pros, cons, experiential, behavioral) at time 2 by the factors at baseline $\left(\mathrm{R}^{2}=.59, .54,53, .46\right.$, respectively).

\section{Precontemplation -> Contemplation}

In this earliest transition subgroup $(\underline{N}=269)$, a 4 factor panel design at baseline and 6 months would not converge on a proper solution due to a constraint on the value of the cons prediction term. Given this problem, the high correlation of the cons factor to the experiential factor in all other models run in the set of panel analyses (range $=.77$ to .91), and in the measurement analysis (.868 at baseline; .850 at 6 months), and the non-significance of any paths of influence of the cons factor on any subsequent factors in other models, a model for precontemplation to contemplation was run without the inclusion of the cons factor at baseline. The cons factor was included at time 2 . This model is shown in Figure 5.

High stability coefficients are evidenced for all three factors $(.76, .66, .51$, respectively). Additionally, a 
significant path coefficient from the experiential processes to the cons factor at time 2 was found (.62). Relative to smokers who remained in the precontemplation stage, smokers who moved to contemplation over a 6 month time period show a pattern in which the experiential processes are influencing their perception of the cons of smoking. As such, as the experiential processes increase, the cons of smoking increase (Table 4). For purposes of moving from precontemplation to contemplation, this model would suggest that smokers increase their experiential process use in an effort to increase their perception of the cons of smoking.

The factor correlations and structural parameters of the model are presented in Table 8 . The model fit to the data indicated a need for improvement, $\chi^{2}(344)=625.398$, TLI $=$ $.858, \mathrm{CFI}=.879, \mathrm{RMR}=.048$. A moderate percent of variance was accounted for in the pros and cons factors at time $2\left(R^{2}\right.$ $=.65, .54$, respectively), and a lesser amount of variance was accounted for in the experiential and behavioral processes at 6 months $\left(R^{2}=40, .31\right.$, respectively). Thus, the focus of movement from precontemplation to contemplation seems to be on the pros and cons of smoking with the influence of the experiential processes on the cons of smoking the most important predictor of change during this stage transition. 


\section{Contemplation -> Contemplation}

In this non-progressive subgroup of contemplators $(N=$ 685), the 4 by 4 factor panel design is again employed (Figure 6). The pros, experiential, and behavioral factors demonstrate high stability coefficients $(.64, .67, .58$, respectively). The model indicates a significant path coefficient from the experiential processes at baseline to the cons factor at time 2 (.70), and a significant coefficient of -.25 from the behavioral processes to the cons factor at 6 months.

This pattern suggests that the emphasis in nonprogressive contemplators remains focused on the cons of smoking. As use of the experiential processes increase, the cons of smoking increase (Table 4). Yet, the decrease in the behavioral processes increases the cons of smoking, although the influence of the behavioral processes is much less than that of the experiential processes. Compared to nonprogressive precontemplators, non-progressive contemplators appear to be more actively involved in affecting their smoking-related attitudes through the influence of cognitive and behavioral smoking strategies and techniques. Contemplators who remain in contemplation also differ from the pattern exhibited from precontemplators who move to contemplation in that they introduce the influence of the behavioral processes in affecting their smoking behavior. 
However, the use of these behavioral techniques works to decrease the negative perception of smoking, and as such, use of behavioral strategies is counter-indicated.

The factor correlations and structural parameters of the non-progressive contemplator subgroup are presented in Table 9. The model fit to the data was good, $\chi^{2}(420)=812.784$, TLI $=.926, \mathrm{CFI}=.938, \mathrm{RMR}=.034 . \mathrm{A}$ moderate percent of variance was accounted for in the experiential and behavioral processes factors at time 2 by the factors at baseline $\left(\mathrm{R}^{2}=\right.$ $.53, .66$, respectively), with a smaller proportion of variance accounted for in the pros and cons at 6 months $\left(R^{2}=49, .43\right.$, respectively).

\section{Contemplation -> Preparation}

The panel analysis for smokers who moved from contemplation to preparation (Figure 7, $\underline{N}=203$ ), indicates two significant stability coefficients for the pros and behavioral processes factors $(.60, .48$, respectively). Two significant diagonal path coefficients are also present from the experiential and behavioral processes to the pros factor at time $2(1.24,-.53$, respectively). The strongest relationship over time is from the experiential processes to the pros of smoking. As the experiential processes decrease, the positive aspects of smoking decrease (Table 4). The behavioral processes are also influencing the pros but to a 
lesser extent. As the behavioral processes increase, the pros of smoking decrease.

Relative to stable contemplators who remain in contemplation at 6 months the smokers who progress to preparation appear to shift to a focus on the pros of smoking rather than on the cons of smoking. Decreasing utilization of the experiential processes of change results in a decrease in the pros of smoking. Conversely, smokers remaining in contemplation seem to be perseverating on the previous strategies that were successful for movement from precontemplation to contemplation. That is, they are still focusing on the cons of smoking and have not switched to focus on reducing their positive perceptions of smoking over time.

For purposes of effective movement from contemplation to preparation, this panel analysis pattern suggests that smokers in contemplation should decrease their use of experiential processes so as to decrease their perceptions of the pros of smoking and, to a lesser extent, begin to focus on the behavioral processes which will also decrease the pros of smoking .

The factor correlations and structural parameters of this transition model are presented in Table 10. The model fit to the data was good although indicating room for improvement, $\chi^{2}$ $(420)=595.381$, TLI $=.893, \mathrm{CFI}=.909, \mathrm{RMR}=.048 . \mathrm{A}$ 
moderate percent of variance was accounted for in the pros and cons factors at time $2\left(R^{2}=.66, .53\right.$, respectively), and a lesser amount of variance was accounted for in the experiential and behavioral processes at 6 months $\left(R^{2}=45\right.$, .36, respectively).

\section{Preparation -> Preparation}

In this non-progressive preparation subgroup ( $\underline{N}=198)$, only one significant coefficient, a stability coefficient from the pros factor at baseline to the pros factor at 6 months, is present (.59). No diagonal paths reached significance (Figure 8), although two positive path coefficients from the cons factor to the experiential and behavioral processes approached significance. This pattern suggests that little stability is present in this stage subgroup. Relative to the previous stage movement transitions, this preparation subgroup pattern appears to indicate little predictive influence of the factors at baseline on subsequent attitudes and behavior over the 6 month follow-up period. However, unlike the similar pattern of precontemplators who remained in precontemplation at 6 months, the preparation subgroup appears far less stable over time suggesting that this group of smokers may be rather transient or less determined in its attitudinal and behavioral disposition. Alternatively, the small sample size of this subgroup ( $\underline{\mathrm{N}}=198)$ may also be contributing to the stability 
problems as well as the inability of the cons factor to emerge as a predictor of the processes of change. While nonsignificant, these relations would suggest that smokers who remain in preparation may focus on the cons of smoking to affect their use of the processes of change. Whether such a focus is counter-indicated to move smokers to action is not discernible without a comparison of the preparation to action staging subgroup.

The factor correlations an structural parameters of the model are presented in Table 11. The model fit to the data was good but indicated room for improvement, $\chi^{2}(420)=$ 583.382, $\mathrm{TLI}=.899, \mathrm{CFI}=.915, \mathrm{RMR}=.044 . \mathrm{A}$ moderate percent of variance was accounted for in all four factors (pros, cons, experiential, behavioral) at time 2 by the factors at baseline $\left(\mathrm{R}^{2}=.41, .58, .66, .45\right.$, respectively $)$, with the highest variability accounted for in the experiential and cons factors at 6 months.

\section{Preparation -> Action}

The panel analysis for the preparation to action group would not converge. This is not surprising given the small number of subjects which defined this group ( $\underline{\mathrm{N}}=76)$. Indeed, the use of structural equation modeling on samples under 100 subjects is discouraged with results from such analyses generally are considered to be unreliable (Boomsma, 1983). 
In an effort to explore this subgroup transition, the pattern of the means at baseline to 6 months was evaluated. Review of the means over time for the four constructs (Table 4) show a pattern wherein the pros, cons, and experiential factors mean scores decrease, while the behavioral processes increase as people move from preparation to action. Conversely, smokers who remained in preparation over the 6 month time period evidenced increases in all but the experiential processes which remained fairly stable. These observations may suggest that much activity is occurring for those people who move to the action stage, and that such activity. may be in the form of increasing reliance on the behavioral processes of change while decreasing reliance on the experiential processes and the pros and cons of smoking. However, such mean level observations do not indicate the influence of, nor the predictive relationships among, the variables over time.

III. Longitudinal Prediction Analyses

Dynamic prediction analyses were conducted to examine the extent to which the model constructs were able to predict change in smoking behavior as measured by the construct, Habit Strength. Habit strength is a composite of two manifest variables: the number of cigarettes smoked per day and the 
temptation to smoke. This analytical approach was used to explore the nature, magnitude and direction of influence of the Transtheoretical Model constructs in predicting the smoking outcome measure. Consistent with Model theory, it was hypothesized that a reduction in the experiential processes and a reduction in the pros of smoking, and an increase in the behavioral processes and an increase in the cons of smoking should be evidenced as a smoker moves to reduce smoking habit strength.

The questions addressed in the prediction analyses are: How much support is there for the various heuristic model integrations as assessed by the predictability of smoking Habit Strength over a period of 6 months by the model constructs? Does the predictability of the various model constructs differ across the stage movement transitions? The longitudinal prediction model is illustrated in Figure 9. A comparison of the model paths for each stage movement transition and non-progressive subgroup is presented in Table 12 .

\section{Prediction Analysis - Total Sample}

In the total sample $(\underline{\mathrm{N}}=3,465)$, the regression paths from the pros, cons, experiential and behavioral processes were all significant predictors of habit strength 6 months later. The largest path coefficient to habit strength was 
from the experiential processes (.721), followed by the pros factor (.477), the behavioral processes factor (-.450), and the cons factor (-.329). Thus, as the experiential processes increase, habit strength increases. The pros of smoking also effect a similar direction of change in habit strength but to a lesser degree. Conversely, decreased use of the behavioral processes results in an increase in habit strength. Decreases in the cons of smoking also effect an increase in habit strength.

Based on this total sample prediction analysis, efforts to effect the outcome variable, habit strength, should focus primarily on decreasing the use of experiential processes and to a lesser degree, on decreasing the pros of smoking, increasing the behavioral processes and the cons of smoking. However, recall once more that the total sample analysis, while not stage based, is probably influenced by the large percentage of precontemplators and contemplators which comprise the sample at both the baseline and 6 month time periods.

The model fit was good, $\chi^{2}(125)=1292.116$, TLI $=.897$, $\mathrm{CFI}=.916, \mathrm{RMR}=.032$. Thirty-three percent of the variance was accounted for in the habit strength factor by the four factors (pros, cons, experiential, behavioral) at baseline. 


\section{Prediction Analysis - Stage Transitions}

\section{Precontemplation -> Precontemplation}

For the non-progressive precontemplation subgroup $\langle\underline{\mathbb{N}}=$ 1,031), The significant path coefficients to habit strength at 6 months were from the behavioral processes factor (-.595) and the pros factor (.570). Thus, as the behavioral processes of change decrease, habit strength increases. Further, as the pros of smoking increase, habit strength increases.

The model fit was adequate but indicated room for improvement, $\chi^{2}(125)=449.127, \mathrm{TLI}=.879, \mathrm{CFI}=.901, \mathrm{RMR}$ $=.034:$ Forty-six percent of the variance was accounted for in the habit strength factor by the four factors (pros, cons, experiential, behavioral at baseline.

\section{Precontemplation -> Contemplation}

For the stage transition from precontemplation to contemplation subgroup $(\mathrm{N}=269)$, a solution would not converge for the 4 independent variable model nor for a three factor (without cons) independent variable model. In both cases, the problem was related to constraints in the error term of the temptation item measuring the habit strength construct. However, mean habit strength endorsement increased over time from 26.56 at baseline to 28.14 at 6 months. 


\section{Contemplation -> Contemplation}

For the non-progressive contemplation stage subgroup ( $\underline{\underline{N}}$ = 685), the significant path coefficients to habit strength at 6 months were from the experiential processes (.557), the behavioral processes factor $(-.492)$ and the pros factor (.424). Thus, as the experiential processes increase, habit strength increases. Of next import is the relationship among the behavioral processes and habit strength wherein a decrease in behavioral processes results in an increase in habit strength. Lastly, as the pros of smoking increase, habit strength increases.

Compared to the non-progressive precontemplator subgroup, the contemplators who remain in contemplation over the 6 month period habit strength appears to be most influenced by the smokers use of the experiential processes, in addition to the use of the pros of smoking and the behavioral processes.

The model fit indicated room for improvement, $\chi^{2}(125)=$ 381.900, TLI $=.858, \mathrm{CFI}=.884, \mathrm{RMR}=.037$. Thirty-nine percent of the variance was accounted for in the habit strength factor by the four factors (pros, cons, experiential, behavioral) at baseline.

\section{Contemplation -> Preparation}

For the stage transition from contemplation to preparation $(\underline{N}=203)$, the significant path coefficients to 
habit strength at 6 months were from the behavioral processes $(-.554)$, and from the pros factor (.417). Thus, as use of the behavioral processes decrease, habit strength increases. Of next import, the pros factor influences habit strength with increases in the pros of smoking resulting in an increase in habit strength.

This progressive pattern of relationships suggests that for those smokers who move from contemplation to preparation, habit strength is influenced by the behavioral processes and perceptions of the pros of smoking. However, compared to nonprogressing contemplators, the habit strength of these smokers are not influenced significantly by the influence of the experiential processes although approaching significance. However based on significant paths only, smokers moving from contemplation to preparation, appear to switch away from a focus on experiential processes in reducing smoking habit strength, with greater influence on habit strength evidenced by the behavioral strategies and a reduction of the pros of smoking .

The model fit indicated room for improvement, $\chi^{2}(125)=$ 202.216, TLI $=.865, \mathrm{CFI}=.889, \mathrm{RMR}=.049$. Thirty-eight percent of the variance was accounted for in the habit strength factor by the four factors (pros, cons, experiential, behavioral) at baseline. 


\section{Preparation -> Preparation}

For the non-progressive preparation stage subgroup $(\underline{N}=$ 198), only one significant path coefficient was found to influence habit strength at 6 months. The most important influencer of smokers who were in the preparation stage and remained in preparation was the pros of smoking factor (.704). Thus, as the pros of smoking increase, habit strength increases.

Compared to the non-progressive precontemplator and contemplator subgroups, the non-progressive preparation subgroup appears to be most influenced only by perceptions of the positive aspects of smoking. Compared to contemplators who moved to preparation, this group appears to continue to be affected by the pros and to a greater extent, but is no longer significantly influenced by the behavioral processes of change.

The model fit indicated room for improvement, $\chi^{2}(125)=$ 202.430, TLI $=.861, \mathrm{CFI}=.887, \mathrm{RMR}=.050$. Sixty-seven percent of the variance was accounted for in the habit strength factor by the four factors (pros, cons, experiential, behavioral) at baseline.

\section{Preparation -> Action}

For this stage transition from preparation to action ( $\underline{N}$ = 76), a proper solution would not converge for the 4 
independent variable model. This is not surprising given the small number of subjects which defined this group $(\underline{\mathbb{N}}=76)$. Indeed, the use of structural equation modeling on samples under 100 subjects is discouraged with results from such analyses considered unreliable (Boomsma, 1983). However, mean response to habit strength indicted a large reduction in perceived habit strength from 24.06 at baseline to 10.47 at 6 months.

III. Model Generalizability

Sex

The longitudinal two-wave panel analysis of the Transtheoretical Model constructs at baseline and 6 months was conducted from the total sample $(\underline{\underline{N}}=3,495)$ for males $(\underline{N}=$ 1,548 ) and females $(\underline{N}=1,947)$ separately (Figure 10 and 11 , respectively). The relationships observed from analysis of each model derived from each sex were then compared to each other and then to the original total study sample in order to explore the consistency of relationships among the posited Transtheoretical Model constructs.

\section{Females}

For the female smokers $(\underline{N}=1,947)$ present in the total sample, four significant stability coefficients were evidenced 
for the pros, cons, experiential and behavioral processes factors $(.39, .26, .30, .26$, respectively). Only one significant diagonal path coefficient was present from the experiential processes to the cons factor at time 2 (.27). Thus, the strongest relationship over time for this subgroup of females is from the experiential processes to the cons of smoking. As the experiential processes increase, the negative aspects of smoking increase.

The model fit was good, $\chi^{2}(420)=2369.146$, TLI $=.935$, $\mathrm{CFI}=.945, \mathrm{RMR}=.029$. A relatively small amount of variance was accounted for in the factors by the pros, cons, experiential and behavioral processes at baseline $(.16, .18$, $.14, .13)$.

Compared to the total sample, the importance of the experiential as the most influential of the constructs to subsequent behavior was maintained as well as the stability of the constructs over time. Unlike the total sample, no other diagonal path was significant. However, the value of the other significant paths in the total sample are far less in magnitude than that of the path from the experiential to the cons of smoking. Thus, this female subsample represents at least a partial replication of the total sample population. 


\section{Males}

For the male smokers $(\underline{\underline{N}}=1,548)$ present in the total sample, three significant stability coefficients were evidenced for the pros, cons, and experiential processes factors $(.39, .47, .28$, respectively). Six significant diagonal path coefficient were present from the cons to the experiential processes factor (.36), from the behavioral processes to the cons of smoking (-.31), from the behavioral processes to the pros of smoking (-.30), from the experiential processes to the cons of smoking (.29), from the cons of smoking to the behavioral processes (.29), and from the behavioral processes to the experiential processes (-.22) Thus; the strongest relationship over time for this subgroup of males is from the cons of smoking to the experiential processes, followed by the behavioral processes of change on the pros and cons of smoking. As the cons of smoking decrease, the experiential processes decrease, and to a lesser extent, as the cons increase, the behavioral processes increase. Similarly, as the behavioral processes decrease, the pros of smoking, the cons of smoking increase, and as the behavioral processes increase, the experiential processes decrease. Lastly, as the experiential processes increase, the cons of smoking increase.

The model fit was good, $\chi^{2}(420)=1639.908$, TLI $=.944$, CFI $=.953$, RMR $=.027 . A$ small amount of variance was 
accounted for in the factors by the pros, cons, experiential and behavioral processes at baseline $(.22, .27, .20, .13)$.

Compared to the total sample, both models demonstrate the significant influence of the processes of change on the cons of smoking at the 6 month time period. However unlike the total sample, the male subsample indicates significant path coefficients to the processes of change from the cons factor at baseline as well at to the experiential factor from the behavioral processes at baseline. Further, the total sample indicates that the cons of smoking influence the pros of smoking at 6 months. No such path is indicated in the male sample: Thus, the role of the cons of smoking is the most salient difference between the male subsample and the total sample.

\section{Female vs Male}

When the male and female samples are compared based on significant path coefficients, the females appear to be focusing primarily on the experiential processes of change for influencers of subsequent smoking attitudes and behavior, while the males are using the cons of smoking and the behavioral processes to influence subsequent smoking attitudes and behavior, as well as being influenced by the experiential processes of change at a similar magnitude. In both cases, affecting the cons of smoking seems important, with the women 
targeting the cons as their singular focus, and men taking a more diffuse approach, attempting to influence all constructs at 6 months at about an equal magnitude.

In both the male and female subgroups, less variance is accounted for in the constructs than that accounted for in the total sample. of most importance, it is not understood whether such relationships observed in the male and female samples will hold or vary depending on the smokers' particular stage of change transition from baseline to 6 months. The discrepancy of the male and female patterns does suggest that such an analysis is needed to determine whether these differences remain present since the overall magnitude of importance of the constructs by sex is rather small and the power to detect differences increases in such large sample sizes. If the observed relations are robust and structural differences exist between males and females, the path differences in sex will remain when staging is taken into account, although the magnitude of influence of the various constructs might vary by sex.

\section{Discussion}

The primary focus of social psychologists is the exploration of causal relationships. We implicitly use models as a framework within which to understand the relationships 
among variables. However, the explicit statement of our causal models forces us to consider our tacit assumptions and biases. Such disclosure allows us to evaluate whether our causal theory matches the model we have chosen to measure it, to modify it if necessary, and to consider the implications of such changes to our understanding of behavior and our application of the model results.

Once a model is posited, structural equation modeling (SEM) techniques allow us to analyze the adequacy of our causal theories. SEM provides a set of procedures for conceptualizing, estimating, and evaluating our posited relationships among our variables. It allows us to explore relationships among and between unobserved latent constructs and observable measured variables. It allows us to posit directional relationships and to assess the predictability of our model on future behavior. In essence, structural equation modeling is a process-oriented technique which allows us to explicitly recognize the logical relatedness between theory and practice.

The purpose of this study was to extend and broaden our understanding of the Transtheoretical Model of Behavior Change by investigating within a single multidimensional framework various heuristic conceptualizations for the structural integration of the Model as a function of staging subgroups, and by exploring general categories of relationships among 
constructs posited by the Model. In doing so, this study represents the an attempt at a systematic approach to building a more fully integrated Transtheoretical Model, both conceptually and structurally, through a series of longitudinal model testing analyses employing latent variable structural equation modeling techniques. Such an analytic plan provided a more rigorous challenge to the predictability of the four major Model components - the pros and cons of smoking and the experiential and behavioral processes of change posited to affect each other in determining behavior change.

The specific intent of this study was to address the following questions through two-wave panel analyses: Which heuristic model conceptualization seems most plausible given the observed predictive relationships among the factors to each other over time (Do attitudes influence subsequent behavior, or does behavior influence subsequent attitudes?)? Do the observed relationships vary as a function of one's stage transition subgroup? What is the direction and magnitude of predictive influence of the Model components to one another over time? Do the observed relationships between variables conform to the theoretical assumptions posited by the Transtheoretical Model? And finally, what is the practical relevance of the observed patterns of relationships to our understanding of the smoking cessation process, and for the design, implementation, and evaluation of effective smoking 
interventions for individuals across all stages of change?

The findings from the panel analyses reveal that the four major components of the Transtheoretical Model, previously examined in isolation or as a function of the stages of change, can heuristically be integrated into a general structural model of behavior change for smoking cessation wherein behavior as measured by the processes of change influences subsequent attitudes as measured by the pros and cons of smoking. The panel results indicated a consistent ordering of effect among the Model components across staging subgroups. Repeatedly, the processes of change influenced the pros and cons more powerfully than the pros and cons influenced the processes of change. Indeed across all staging subgroups, there is no case where the pros and cons of smoking predict subsequent experiential or behavioral process use. This processes-driven pattern of relationships among the Model components implied that the processes may be most appropriately viewed as the independent variables in the Transtheoretical Model of Behavior Change initiating subsequent cognitions and behavior, while the pros and cons of changing behavior may be most appropriately viewed as the mediators between the processes and behavior (Figure 1). However, the relationships between the processes and the pros and cons is not meant to imply a sequential ordering in the "causal" sense. That is, the model components are not causing 
each other alternatively or exclusively. Rather, all variables influence behavior in an interactive process. Yet, to the extent that this study demonstrates the processes of change exhibiting the most predictive influence on the decisional balance factors over time rather than the pros and cons influencing the processes of change, a heuristic sequencing of the Model can be proposed to facilitate understanding of the structuring of the behavior change process.

With respect to methodological strength, the study explicitly employed all four model constructs at baseline and at 6 months in the cross-lagged panel design. This approach takes into account the interactive relationships existing between the variables at each of the two time periods. As such, confidence in the results that the processes of change are a primary influence on subsequent behavior is increased over and above model testing that looks at path relations among variables independently at different points in time. Additionally, this study used longitudinal rather than crosssectional data, looking at Model relations over a substantial time period of 6 months. The temporal challenge to the Transtheoretical Model provides a more valid test of the nature and stability of predicted Model structure and construct relations. Further, the finding that a structural pattern held true regardless of where smokers were along the continuum of readiness to change, provided further support for 
proposing a processes-led theoretical sequencing of the behavior change process.

When looking at the specific stage-based panel analyses, the direction and magnitude of the influence of the four major Model components over time varied as a function of stage movement and non-movement subgroups. Dependent on one's stage of change, progression to the next stage required differential employment of the four Model components. For example, successful progression from precontemplation to contemplation, and then from contemplation to the preparation stage change appears to begin with a focus on increasing the use of experiential processes which increase the cons of smoking for progression to contemplation, but then switches to a focus on decreasing the experiential processes which decrease the pros of smoking together with an increasing of the use of behavioral processes to decrease the pros of smoking to move the smoker to the preparation stage.

This switch from increasing experiential process use in order to increase the cons of smoking to decreasing experiential processes use in order to decrease the pros of smoking is of critical importance when you examine the nature of the variable relations in the nonprogressive stage subgroups. For precontemplators who stayed in precontemplation, no significant influential activity emerged across any of the Model components over time and the mean 
level of activity was lowest for this subgroup consistent with Model theory (Prochaska \& Diclemente, 1983, 1984). Only with an increase in experiential process use does a recognition of the cons of smoking begin to emerge and move the smoker to begin contemplating smoking cessation. However once in contemplation, the inability of the smoker to decelerate utilization of the experiential processes of change appears to keep the smoker in contemplation, chronically thinking about the negative aspects of smoking. While utilization of the experiential processes was effective in moving the smoker out of precontemplation, movement from contemplation to preparation now requires the smoker to actively reduce use of experiential processes. Perseveration of the previous experiential strategies now serves to exacerbate cognitions of the positive aspects of smoking.

It as at this juncture between contemplation and preparation that behavioral strategies begin to play a significant role in subsequent attitudes related to smoking. of lesser influence than experiential processes for stage progression from contemplation to preparation, behavioral strategies and techniques begin to exert significant influence by reducing the perceptions of the positive aspects of smoking rather than affecting perceptions of the cons of smoking. Indeed, for smokers who remained in contemplation, as behavioral strategies decreased, the cons of smoking 
increased. This finding suggests that increased use of behavioral strategies is counter-indicated for contemplators if targeted at the cons of smoking.

For smokers who went from preparation to action over time, no successful model was run due to the small sample size. However investigation of the mean level of endorsement of the Model components over time suggests that behavioral processes increase over time while the use of the pros and cons decrease and the experiential processes remain fairly stable. While this pattern may suggest a growing influence of the behavioral processes as a smoker continues into action relative to the other Model components, as Model theory would contend (Prochaska \& DiClemente, 1983, 1984), the predictive influence of the behavioral processes on subsequent attitudes and behavior cannot be assessed without conducting the path analysis for this stage subgrouping.

Thus, across all staging subgroups where significant regression paths were indicated ( $\mathrm{PC}->\mathrm{C}, \mathrm{C}->\mathrm{C}, \mathrm{C}->\mathrm{PA}$ ), the most important influencer of subsequent attitudes over time was the experiential processes of change, followed by the behavioral processes of change. The processes of change always predicted subsequent attitudes (pros or cons), but did not influence each other over time. In no panel analyses for the staging subgroups did the pros and cons influence either subsequent attitudes or behavior. Further, the cons factor at baseline 
never resulted in a significant stability coefficient across any of the panel analyses for the subgroups. This latter finding may be due to the high correlation of the cons factor to the experiential factor at baseline. However, only when looking at the relationships of the components over time without consideration of the stage subgroupings, does the cons factor emerge as a weak but significant and negative related influencer of the pros of smoking at 6 months.

In the total sample panel analyses, the experiential processes once again emerge as the most significant influencer of both the pros and cons of smoking, followed by the behavioral processes of change influencing the pros and cons of smoking. This finding is not surprising given that the total sample is predominantly comprised of smokers in the precontemplation and contemplation stages of change.

The most important lesson from comparing the total sample with the staged panel analyses is the realization that examination of the total sample masks the critical differences that emerge as a function of a smokers stage of change. Assessment of variable relations for the prediction of behavior and for maximally understanding the behavior change prociess must be considered a standard statistical analysis with classification information on subjects' stages of change part of the standard set of demographic information currently provided in all research publications. 
While the panel analyses strongly support the Transtheoretical Model's contention that the experiential processes construct is the most significant influencer of movement out of the precontemplation and contemplation stages, and that this influence should be stronger relative to the behavioral processes of change (Prochaska \& DiClemente, 1983, 1984), several other general types of relationships between constructs should also be observed within the context of the more fully integrated model. For example, this study replicated the finding of previous studies that the behavioral processes do not appear to play a significant role until the smoker begins to approach the later stages of change (Prochaska \& Diclemente, 1983, 1984). Model theory also posits that the evaluation of the pros and cons of decisional balance should be more influential in the early stages of change consistent with their status as predictors of movement from precontemplation and contemplation to the action stage of change, after which they decline in saliency (Prochaska, et al., 1992).

In this study, the significance of the pros and cons of smoking as independent variables of subsequent attitudes and behaviors was not evidenced in the panel analysis for precontemplators who move to contemplation nor for contemplators who move to preparation as would have been predicted by Model theory (Prochaska, in press). This finding 
may partially be explained by the fact that many previous investigations of the decisional balance construct examined the pros and cons in isolation rather than simultaneously with other Model components within a general structural modelling framework, and looked at Model relations cross-sectionally or cross-sequentially rather than longitudinally as was done in this study. While it is true that several longitudinal and predictive investigations of the model variables and constructs have been conducted, these studies have looked at the model variables as predictors of progress across the stages over time using discriminant function analysis or multiple regression techniques wherein model variables are entered simultaneously in an effort to predict future outcome or stage movement (Prochaska, et al., 1985; Velicer et al., 1988; Wilcox, et al., 1985), or have used panel analyses to predict habit strength from the pros and cons of smoking constructs only (Velicer et al., 1992). Unlike the current study, these latter analyses of model component relationships are not within a single, multidimensional framework in which model constructs are simultaneously employed to predict themselves and the other model constructs over time. Further, the use of structural equation modelling techniques is a more powerful technique than discriminant function analysis or multiple regression as it allows for the consideration and isolation of measurement error and the modelling of correlated 
errors across constructs over time.

The lack of a significant independent influence in these present panel analyses does not preclude a direct mediating influence of the pros and cons of smoking on smoking outcome behavior in which the pros and cons act as mediators or intervening variables in the fully conceptualized structural Model. However, a strong independent influence is not predicted by Model theory as the pros and cons of smoking are less salient constructs during the later stages of change where such outcomes as smoking cessation are appropriate.

While the primary intent of this study was not to investigate smoking outcomes but to further understand the relationships among the four major model components, dynamic prediction analyses were conducted with respect to a smoking outcome measure - habit strength - as a function of the stage subgroupings. Habit strength was chosen as an outcome measure because it had the most promise of being sensitive to the change process across the stages of change relative to more dichotomous measures of smoking (Velicer et al., 1992).

In as much as the proposed heuristic model conceptualization from the panel analyses suggests that the processes influence smoking outcome through the pros and cons of smoking, evidence of the more proximal role of the pros and cons might be anticipated to evidence themselves in the prediction analyses. Further, the Transtheoretical Model 
posits that two general types of relationships should exist in this prediction framework: the behavioral processes and the cons of smoking should be negatively related to smoking outcome (habit strength), and the pros of smoking should be positively related to smoking outcome (Prochaska et al., 1992; Prochaska et al., in press).

of the five prediction models that were successfully completed, (total sample, PC->PC, C->C,C->PA, PA->PA), the direction of influence of significant constructs on habit strength was consistent with that proposed by theory (See Table 12). Where significant, the experiential processes and pros of smoking were positively related to habit strength indicating decreased use of these components to reduce smoking habit strength, and the cons of smoking and behavioral processes were negatively related to habit strength suggesting their increased use to reduce habit strength.

Specific to the stage subgroupings, all the successfully completed prediction models evidenced the influence of the pros construct on subsequent smoking habit strength. This finding is consistent with Model research positing a "weak principle of change" which states that progress from precontemplation to action is a function of a $1 / 2$ standard deviation reduction in the pros of smoking (Prochaska, in press). Additionally, the influence of the behavioral processes was evidenced to an even greater extent in all the 
models excepting the non-progressive preparation to preparation subgrouping. In this subgroup only the influence of the pros of smoking on habit strength was evidenced. This pattern is consistent with the panel analysis for this subgroup which also only indicated the influence of a stability coefficient of the pros factor.

Unlike the repeatedly significant role of the experiential processes construct in the panel analyses, the influence of the experiential factor on habit strength is only evidenced in the non-progressive contemplation subgroup as well as in the total sample which is primarily comprised of smokers in the precontemplation and contemplation stages of change. Compared to contemplators who move to preparation, non-progressive contemplators appear to rely more on the experiential processes when they should be relying more on the behavioral processes to affect change in Habit strength.

As was true for the panel analyses, the role of the cons of smoking does not emerge in any of the prediction models as a significant influencer of habit strength over time except in the total sample panel analyses where stage of change is not taken into consideration. This result is consistent with Model theory that posits that the role of the cons is most important for movement from the precontemplation stage to contemplation where smoking behavior does not change, declining in saliency in the later stages where smoking 
cessation as an outcome becomes of issue. This result is also consistent with a previous study of the pros and cons of smoking (Velicer et al., 1992) in which a five-wave panel analysis of the relationships among the pros and cons to habit strength did not indicate a significant role of the cons to smoking behavior. Together, these results suggest that smokers should not focus on emphasizing the negative aspects of smoking but spend more time trying to reduce the positive aspects of smoking if efforts to reduce habit strength are to be maximally effective, and that these efforts should be done together with an increase in behavioral strategies and techniques.

Given Model theory which posits a "strong principle of change" stating that progress from precontemplation to action is a function of 1 standard deviation increase in the cons of smoking (Prochaska, in press), the non-significant predictive role of the cons in these analyses downplays this Model components role when considered simultaneously with the experiential and behavioral processes of change and the pros of smoking within a general structural model framework and two-wave panel design of the same constructs over time. However, given the absence of a stage subgrouping reflecting the movement from precontemplation to action and from preparation to action, caution in this interpretation is warranted. Additionally, the high correlation between the 
experiential processes of change and the cons factor at baseline across panel analyses (mean $=.85$ ) may indicate the source of the problem since the correlation decreases significantly at 6 months in all panel analyses. Indeed, the self-reevaluation item of the experiential processes construct is highly related to the cons factors. However, removal of the item did not significantly decrease the correlation. Such a problem may disappear if the two constructs are measured with a larger number of manifest variables to broaden the breadth of content as is available in the long form of these construct measures in an effort to reduce their similarity. However, it is also plausible that the correlation between the two variables will remain, requiring consideration as to whether the cons factor is really an important contributor to the Model structure. Indeed, the correlation between the constructs was much reduced at 6 months suggesting that the relationship is an artifact of only cross-sectionally measuring variables that are sequentially related.

Evaluation of the percent of variance explained in smoking habit strength by the pros and cons of smoking and the experiential and behavioral process factors results in explaining the greatest variance in habit strength for the nonprogressive preparation subgroup (.67) followed by the precontemplation subgroup (.46). While speculative, it is possible that the habit strength outcome, which represents the 
number of cigarette smoked and the temptation to smoke remains primarily a dichotomous action-no action outcome measure. This possibility might explain the greater variance explained in the two staging subgroups which represent the extreme ends of smoking intention where smokers are ready to take action (smokers in preparation) and smokers not intending to take action (precontemplation). Further, the relative nondifference of the pattern of relations across subgroups (all stage subgroupings reflected the influence of the pros and behavioral processes and at relatively similar magnitudes) might be explained by an inability of the habit strength measure to be sensitive enough to detect differences in nonaction oriented stage subgroupings.

Indeed, some cautions need to be raised related to the habit strength construct in this study. The measurement analyses indicated that the construct was dominated by the temptation manifest variable, with an extremely low factor loading for the number of cigarettes smoked manifest variable. In as much as the habit strength construct represents "temptation level", the relative non-difference among the patterns of relationships among the various stage subgroupings in predicting subsequent habit strength may be partially understood.

Research to date suggests that level of temptation may be a more important predictor of the relative use of the 
processes of change during the precontemplation and contemplation stages of change, but a more important predictor of movement into action and maintenance than from precontemplation to contemplation (DiClemente et al, 1985). Thus, although temptation levels decrease linearly across the stages of change as evidenced in this study and others (DiClemente et al., 1985), the temptation construct as a dependent variable may still not be adequately sensitive to the early stages of change but more appropriate during the later stages of change. Consistent with this notion, the prediction models across the stages suggest that the behavioral processes, utilized most frequently in the later stagè of change, consistently emerge as strong influencers of habit strength across all stage subgroupings but did not emerge in the panel analyses of the stage subgroupings. Indeed the pros of smoking never emerge as independent variables in the panel analyses.

This initial but tentative pattern of results of the prediction analyses provide additional support to the heuristic model which posits the processes of change as independent variables and the decisional balance constructs as mediator variables in the more fully integrated conception of the Transtheoretical Model of Behavior Change and, excepting for the cons factor, supports the general types of relations proposed by the Model. 
In a preliminary effort to investigate the generalizability of a more structurally integrated Transtheoretical Model of Behavior Change, a total sample longitudinal panel analysis of the four model constructs over time was investigated as a function of sex. The results by gender indicated that for the female subsample, the experiential processes construct was significant although a minimal influencer on subsequent attitudes as represented by the cons of smoking at the 6 month time period. The direction of influence of the experiential processes factor was positive as is consistent with the findings for the total population sample and the stage subgroupings previously analyzed. For the male subsample, a much greater number of significant path coefficients were evidenced although all were at a similarly small magnitude. The strongest relationship for the subgroup of males was from the cons of smoking to the experiential process of change. The cons path coefficient is positively related to subsequent experiential strategies and techniques. However in the same model, the experiential processes of change also predict the cons of smoking over time.

Given the low magnitude of all of the significant path coefficients and the greater power to detect significance with such a large sample size, meaningful interpretation of the male and female path patterns must await further investigation as a function on stage movement subgroupings. However these 
initial results do suggest that the model relations may differ as a function of sex since the breakdown of the total sample by gender did not completely replicate the total sample. Additionally, the Model structure and relations should be assessed for generalizability to specific ethnic populations. By investigating the model construct relationships as a function of ethnicity and sex, we recognize the need to consider the possibility that the magnitude of influence of various Model constructs may differ among populations or that certain constructs may require content redefinition to be more culturally sensitive and specific.

Other potential study limitations should also be noted. First; the method of data collection is self-report from smokers recruited by telephone to participate in the study. However, this method of recruiting smokers was proactive and involved a random survey among a population of all possible households in the state of Rhode Island rather than being a reactive recruitment which may result in a less representative sampling pool. In addition all subject non-respondents over time were followed up by telephone to complete their questionnaires.

Yet, the self-report mode of data collection needs to be considered in future research to determine whether the pattern of relations observed are primarily a function of biases 
arising from self-report. However, if such a bias exists and responses are influenced by social desirability, the bias would probably be in the direction of over-reporting quit attempts. This would result in a higher number of smokers in later stages of change at the $\sigma$ month time period. Yet, evaluation of the stage classifications are consistent with stage classification profiles found in other studies across different health areas and with various populations.

Second, the generalizability of the more fully integrated Model structure and posited relations needs to be replicated with other sample populations and across health areas other than smoking. Further, the results of this study should be validated with the existing longer forms of the measures to assess whether the findings replicate. The measurement analyses conducted in this study do suggest some minor issues that need to be resolved related to the habit strength variable and the relationship between the cons factor and the experiential processes factor. Yet overall, the measurement models in this study provided reasonable fit to the data (Table 13). Further, structural confirmation of the short form instruments has been conducted in a prior study of smokers and indicated excellent model fits (.94 to .99), replicating the same hierarchical structures of the long forms (Fava et al., 1991).

Third, a note should be made about the various sample 
sizes employed for the testing of the different staging subgroups. The greater the sample size, the more power that exists to detect significance in the regression paths. Appropriate caution should be taken when interpreting the relevance of small path coefficients, and similarly in assuming the relevance of a lack of a significant path coefficient in the analyses. Indeed, where indicated, mention of paths approaching significance in the analyses is made in the manuscript and tentative interpretations proffered.

Fourth, measurement of higher order factors instead of item level variables and specific scales was conducted in this study with the experiential and behavioral processes of change. Measurement at the construct level does not allow us to understand the role the specific processes play in affecting behavior or when they impact on behavior during the change process. For example, the experiential processes construct is comprised of 10 items with 2 item scales defining each of 5 specific cognitive strategies and techniques that people employ when attempting to change behavior. Which of these processes are most critical at what stage of change and to what magnitude is of considerable interest and should be investigated in future analyses to provide an even more microlevel understanding of the Model relationships over time and as a function of the stages of change. It is also possible that the direction of the relationship between the processes 
and the pros and cons may be a consequence of the mixed levels of measurement used in the models. Higher order factors are more likely to be heterogeneous than more narrowly defined constructs and, other factors being equal, may therefore be better predictors of a dependent variable. The greater breadth and variety of content included in a higher order construct should increase the likelihood that at least some constituent aspect of the construct is related to the predicted construct.

A fifth limitation is the mixture of samples that are being intervened on with samples that are not being so intervened. This potential confounder is a problem only in as much as such intervention can be said to change the structural relationships among the constructs. The Transtheoretical Model posits general structural relations among key constructs which all individuals negotiate during the change process whether that change occurs on one's own or within the context of professional intervention. The purpose of this current study is not to look at intervention effectiveness, but rather to learn from the successful and non-successful changers regardless of their particular cues to action.

Finally, structural equation modeling techniques were employed to evaluate three different aspects of the Transtheoretical Model, measurement structure, Model construct relations, and Model construct predictions through confirmatory factor analyses, panel analyses, and dynamic 
prediction analyses. SEM moves beyond the dichotomy of theory and application and permits a more comprehensive, multifaceted, and multidimensional investigation of our causal inferences in a more valid and reliable way than other techniques alone. Yet, SEM is a correlational technique and therefore can never claim to ascertain causality in any of these model testing approaches (Cliff, 1983). In fact, no statistical technique can ever test causality. Rather, SEM allows us to model our causal assumptions and to disconfirm their validity as specified. If driven by theory, SEM techniques are powerful tools for explicating the implications and applications of our causal theories. By allowing us to model the real world complexity of human behavior, structural equation modeling provides a powerful set of procedures that satisfy the criteria of rigor and utility that should be demanded by both science and practice. So, what is the practical relevance of this empirical investigation to the application and implementation of the Transtheoretical Model? The utility of the Model's integration is evident when considering strategies for designing, conducting, and evaluating smoking cessation programs. It provides a plan and a strategy for achieving maximum effectiveness in reducing smoking behavior.

For example, in the proposed processes-driven conceptualization of the structural integration of the 
Transtheoretical Model, the processes of change are the independent variables in the Model. As such, for intervention purposes, one would focus on designing interventions that used these strategies and techniques in order to influence behavior change. The mediator variables would be the pros and cons of smoking. As intervening variables, they would serve as the diagnostic indicators one would use to assess the extent of progress evidenced by a smoker in a smoking program as a function of processes used. Further, evaluation of success would no longer be based on the dichotomous outcome variable smoking/not smoking, but would be based on process-to-outcome mediating variables which more accurately reflect the changes occurring for those smokers who are not yet ready to quit smoking. Knowing what the mediating and independent variables are that are most influential at any given stage of change allows us to fine tune our intervention strategies and to measure success by appropriate indicators.

While Model research to date together with this current study provide ample evidence of the Model's theoretical and practical relevance for understanding and identifying the determinants of the behavior change process, the ability to translate and transfer this technology for dissemination, implementation, and diffusion is quite another matter. To the extent that the application of the Transtheoretical Model remains confined to adoption of the stages component only 
while other Model components remain isolated from the total Model and under-utilized, the synergistic benefits of the structurally integrated Model will reside in the minds of interventionists and program designers as yet another unrealistic theoretical ideal.

Given the theoretical complexity of the more fully integrated Transtheoretical Model to most practitioners and the logistical complexity of completely and adequately applying the various Transtheoretical Model components simultaneously to change behavior, innovative technologies need to be developed to facilitate implementation of the Model so that a reduction in smoking behavior may be achieved. Diffusion theory states that innovations must be easy to use, possess "trialability", have immediate feedback, relatively low cost, and be compatible with the existing culture to be readily diffused (Rogers, 1983). One such technology that meets these criteria is an expert system. Currently, an expert computer system has been developed for delivery of individual behavior change programs based on the Transtheoretical Model of Behavior Change (Velicer et al., in press).

The use of expert systems which target multiple risk factors for individuals and provide personalized and interactive feedback would be a major achievement in the health promotion field. The notions of segmenting, sequencing and timing, in essence orchestrating the intervention, are 
built in and can be delivered to a group or site. while providing individually appropriate and targeted interventions. Evaluation is ipsative and normative such that feedback about one's behavior relative to others is a source of normative information. The technology is transferrable to any setting, has low maintenance costs, and requires minimal personnel for upkeep increasing the likelihood that such a system will be institutionalized. Updates of the system are feasible, and the feedback provided is more consistent as it is based on a program which can handle more parameters in its interpretation than any one individual. Most importantly, the user need not understand the process of change and the theory behind the Transtheoretical Model to effect considerable change in the population of interest.

To enhance the capacity of an individual to effectively engage and maintain change, however, attention to the physical and institutional applications of the technology is recommended. Providing some summative information to the organization, school, community etc. would provide a way of reinforcing the involvement of the change agent, provide an important tool for the organization to use for public relations externally and with their personnel or customers. The feedback given to the community or organization would allow normative feedback to be posted within the site as an additional cue and reinforcer in the environment. Group 
progress could be monitored and provide incentive. Progress could also be evaluated appropriately as a function of stage of change such that users could see intermediate progress gains rather than perceiving yet another program fail due to inappropriate measures of program success. Further, such information would provide the user organization information that, if collected from the individuals, could be used to influence institutional change within the organization or agency. For example, food choices might be altered as a result of information gathered. Additionally, the expert system provides an important means of accessing the laggard who might be socially isolated and not targeted in any other social channel, and for the precontemplator who might be resistant to participating in more reactive health promotion appeals.

Lastly, the expert system could also be modified and adapted to provide an assessment of the readiness level or stage of the worksite, school, health care center, etc. that would enable agencies which diffuse information to know where sites are in their readiness to engage in intervention activities, and which activities are most appropriate to conduct at the organizational or community level. The top down dissemination process could then occur in parallel to that of the bottom-up approach of individuals within the organizational setting.

Evaluation of this innovation by the diffusion formula of 
Impact $=$ Effectiveness $\mathrm{X}$ Dissemination $\mathrm{X}$ Fidelity, and Efficiency = Impact/Cost, bodes well for the expert system which is readily disseminable to large numbers of people, sites, and repeatedly, is guided by the Transtheoretical Model of Behavior Change which has proven effectiveness in changing behavior, and targets by stage across multiple health risks in a maximal order, and maximizes fidelity by demanding low skill to operate. Further, behavior change strategies recommended to the participant need not be done faithfully for the intervention to work. The individual receives ipsative and normative feedback from the last time as the computer tracks progress and uses the information to prompt change. Maintenance costs are minimal relative to impact.

Using the expert system technology as an outreach strategy and medium to effect change is a comprehensive approach which permits the integration and delivery of all the Transtheoretical Model components into a transferrable whole. The adaptability of the expert system and the Transtheoretical Model to work in conjunction with community approaches to health promotion serves as a value-added bonus to the dual technologies. Through this medium of expert computer systems, the Transtheoretical Model may be employed to develop stateof-the-art interventions for prevention and cessation activities which are more likely to be adapted by practitioners and more readily transferrable to target 
audiences. Future success of the Model will be based on its ability to present itself as a parsimonious, user-friendly, and practical guide for intervention development and evaluation without detracting from its explanatory and predictive power.

Other future Model research should be aimed at yielding an even more microlevel understanding of the Model construct relations, and the generalizability of the Model structure and its Model component relations when applied to ethnic populations other than predominantly white populations. Such initial work has already been done with findings supportive of the utility of the Model in different populations (Gottlieb, et al., 1990; Pallonen, et al., 1992). Future investigations should also attempt to compare alternative behavior change constructs from competing health models, community and organizational approaches, and diffusion theories with that of the Transtheoretical Model of Behavior Change in an effort to identify additional components which should be considered for inclusion into the Model in keeping with its tradition as an eclectic and continually evolving Model of behavior change.

The Transtheoretical Model moves beyond alternative behavior models (i.e., Health Belief Model, Social Cognitive learning Theory, Theory of Reasoned Action) as it is both a behavior change model and a prediction model. Through the quasi-exploratory model testing techniques used in this study, 
a more fully understood Model has emerged which provides guidance for increasing intervention effectiveness consistent with the purpose behind behavior change models. Through investigation of the heuristic structure of the Model components across staging subgroups, a more structurally integrated Transtheoretical Model of Behavior Change is posited that helps elucidate the relative importance of proposed determinants of the change process. This function is consistent with the role of prediction models of behavior. Indeed, the differential nature of relations across the stage of change subgroups allows us to more completely understand not only how people move from one stage of change to the other, but also what behavior is potentially causing smokers to remain static in their smoking behavior.

In essence, this study represents an initial attempt to more fully explain and predict the behavior of the Transtheoretical Model of Behavior Change by turning the Model's explanatory and predictive functions upon itself. It is only through rigorous model testing that movement of the Transtheoretical Model through its developmental stages of change will occur. However, such movement is not linear but spiral, requiring a continual revisiting, challenging, and refining of our assumptions of the behavior change process more generally, and the behavior change process of smoking cessation more specifically. 


\section{SMOKING FOLLOW-UP}

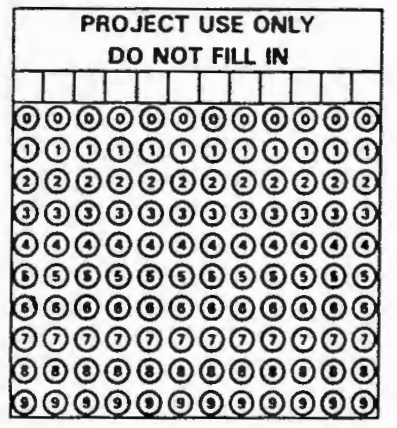

\section{INSTRUCTIONS}

Please answer the following questions based on your experiences with smoking. Each question allows you to choose from several altermatives. Please select the appropriate response and fill in the corresponding circle Bo sure to answer each question. Use only a NUMBER 2 PENCil. and blacken the circle completely. Make no stray marks on the answer sheet.

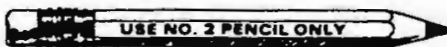

\section{Right Mark}

Wrong Mark $\$ \otimes O O$

1. Are you currently a cigarette smoker?

ONo

OYes

2. Are you seriously considering quitting within the next six months?
OnO
OYes
Ol do not smoke

3. Are you planning to quit in the next 30 days? ONo

OYes

Ol do not smoke

4. Have you smoked ANY cigarettes in the PAST 24 HOURS?
ONo
OYes

5. Have you smoked ANY cigarettes during the PAST MONTH?

$$
\text { ONo }
$$

6. SINCE OUR LAST CONTACT WITH YOU, have you smoked ANY cigarettes at all?

$$
\begin{aligned}
& \text { Ono } \\
& \text { OYes }
\end{aligned}
$$

7. SINCE OUR LAST CONTACT WITH YOU, how many times have you quit smoking for 24 hours or more? (If more than 9 times, put 9)

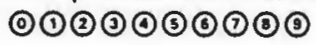

8. IN THE LAST YEAR how many times have you quit for at least 24 hours? (If more than 9 times, put 9)

()(2)(3)(5)(이이
9. Do you currently smoke a pipe, cigars, or use other tobacco products (other than cigarettes)?

$$
\text { Ono }
$$

10. How confident are you that you will be able to stop smoking at this time? (If you do not smoke. how confident are you that you will be able to stay off at this time?)

$$
\begin{aligned}
& \text { ONot at all confident } \\
& \text { OSomewhat confident } \\
& \text { OModerately confident } \\
& \text { Overy confident } \\
& \text { OExtremely confident }
\end{aligned}
$$

11. SINCE OUR LAST CONTACT WITH YOU, how much material about smoking have you read?

$$
\begin{aligned}
& \text { ONione } \\
& \text { OA little } \\
& \text { OSome } \\
& \text { OQuite a bit } \\
& \text { OA bit }
\end{aligned}
$$

12. SINCE OUR LAST CONTACT WITH YOU, hOW often have you used information you have read about smoking?

$$
\begin{aligned}
& \text { ONeves } \\
& \text { OSeldom } \\
& \text { Ooccasionally } \\
& \text { OOtten } \\
& \text { ORepeatedly }
\end{aligned}
$$

13. How helpful were the materials that you have read abour smoking?

ONot at all helpiul

O Sornewhat hetplut

OModerately helpful

OVery hetpfu

OExiremely hepplul 
SMOKING FOLLOW-UP (continued)

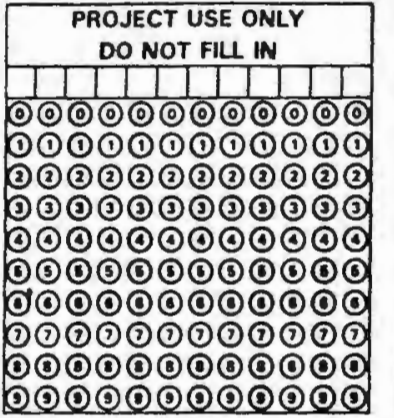

\section{INSTRUCTIONS}

B

Please answer the following questions based on your experiences with smoking. Each question allows you to choose from several altematives. Please select the appropriate responses and fill in the corresponding circles. Be sure to answer each question. Use only a NUMBER 2 PENCIL and blacken the circles completely. Make no stray marks on the answer sheet.

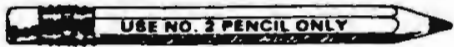

Right Mark

Wrong Marks (S) $\odot O$

14. SINCE OUR LAST CONTACT WITH YOU. what is the longest period you have gone without a single cigarette? (If you have not quit for 24 hours or more put 0000 .)

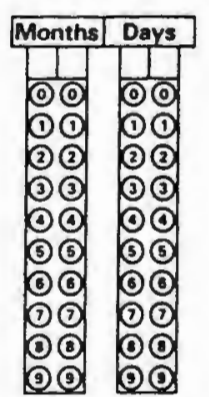

15. During the past 7 days how many cigarettes did you smoke on a typical day? (If you didn't smoke put 00 , if you smoked less than one a day put 01.)

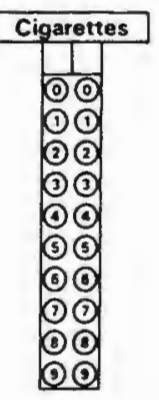

16. How soon after you awake do you usually smoke your first cigarette? (If you don't smoke put 0 00.)

\begin{tabular}{|c|c|}
\hline Hours & Minutes \\
\hline & \\
\hline (1) & (1) \\
\hline (2) & (2) (2) \\
\hline & \\
\hline (5) & (5) \\
\hline & () \\
\hline 8 & Q \\
\hline D & (7) \\
\hline
\end{tabular}

17. How much do you weigh now in light indoor clothing without shoes? Please round to the nearest pound.

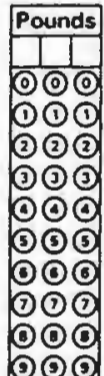

18. SINCE OUR LAST CONTACT WITH YOU, which of the following have you used in your efforts to quit smoking? (If you have not tried to quit, fill in "No" for each item.)

Cold turkey (aurting all at once)

Gradualiy cutting down

Nicorette gum

Other drugs prescribed by your doctor

Professional stop smoking clinic

Hypnosis

Support group

Self-help manuals or books

Other

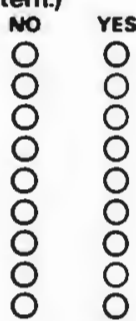

19. IN THE LAST 7 DAYS have you used any nicorette gum or other drugs prescribed by your physician to control your smoking?
OYes 


\section{TEMPTING SITUATIONS}

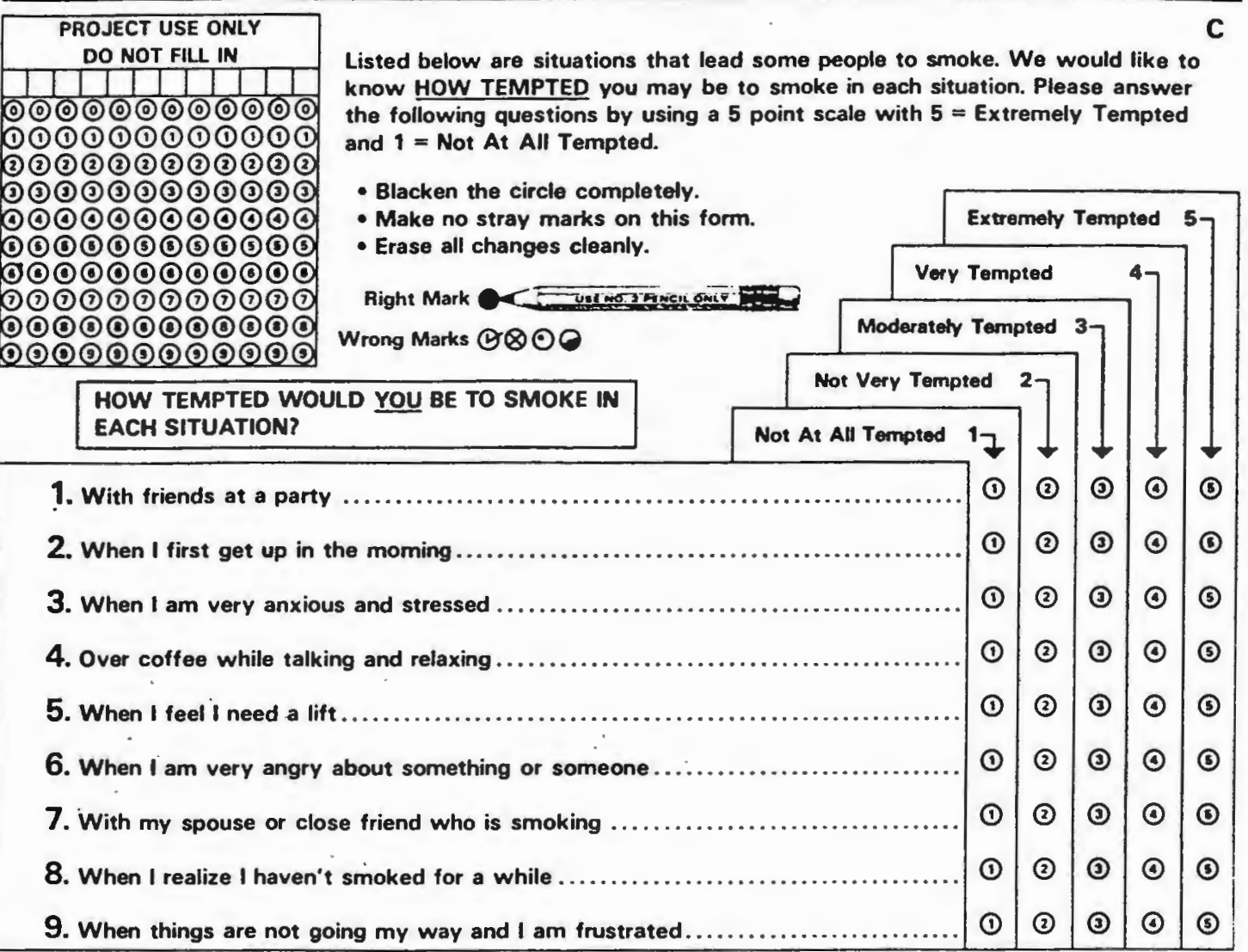

\section{PROS AND CONS}

The following statements represent different opinions about smoking. Please rate HOW IMPORTANT each statement is to your decision to smoke according to the following 5 point scale with $5=$ Extremely Important and $1=$ Not Important.

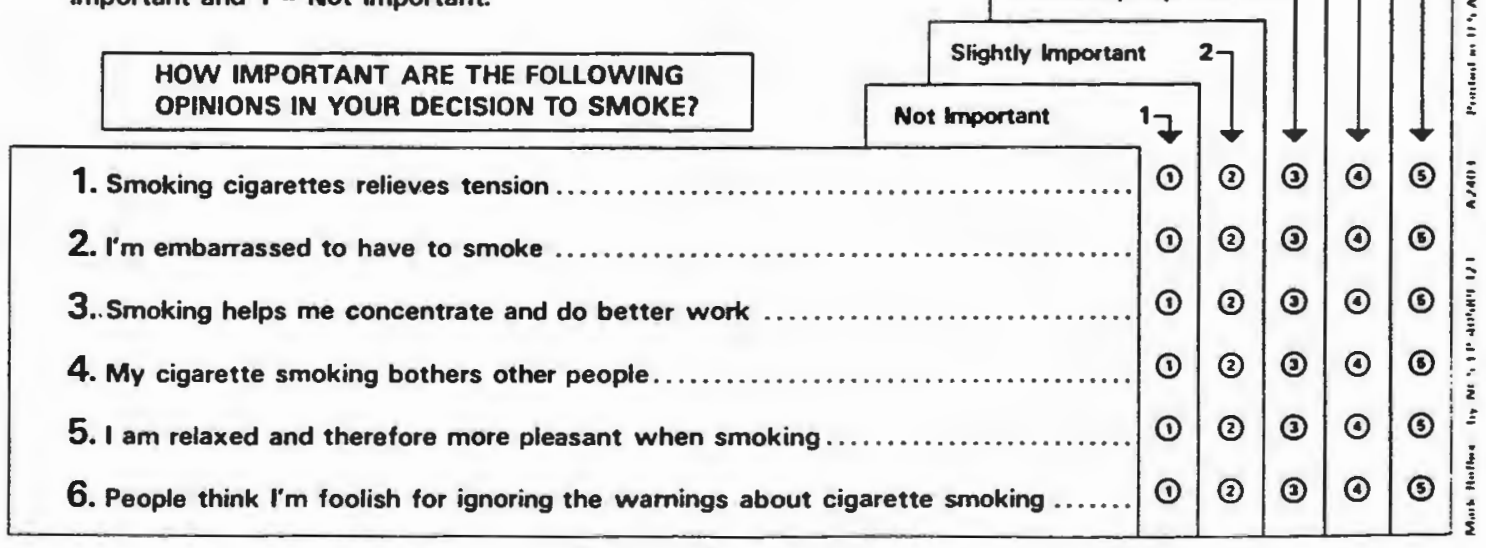




\section{IMPACTS ON SMOKING}

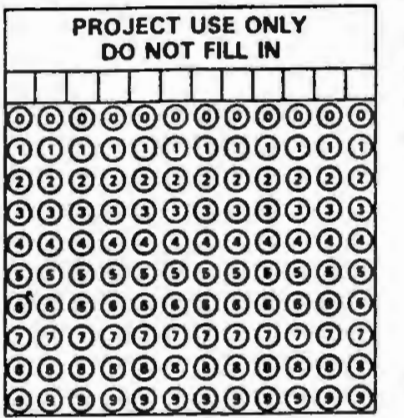

The following experiences can affect the smoking pattem of some people. Think of any similar experiences you may be currently having or have had in the last month. Then rate the FREQUENCY of each event on a 5 point scale with $\mathbf{5}=$ Repeatedly and $\mathbf{1}=$ Never.

- Blacken the circle completely.

- Make no stray marks on this form.

- Erase all changes cleanly.

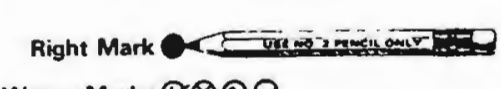
(90000000000

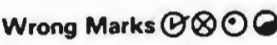

1. When I am tempted to smoke, I think about something else
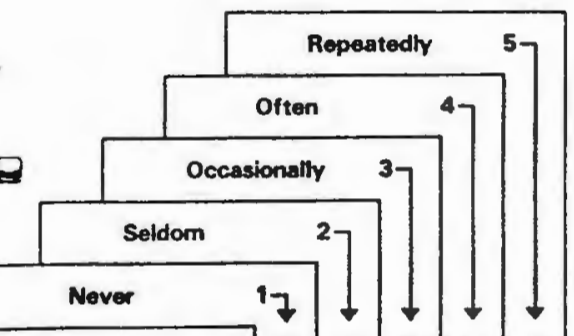

2. I tell myself I can quit smoking if I want to

3. I notice that nonsmokers are asserting their rights

4. I recall information people have given me on the benefits of quitting smoking

5. I can expect to be rewarded by others if I don't smoke

6. I stop to think that smoking is polluting the environment

7. Wamings about the health hazards of smoking move me emotionally

8. I get upset when I think about my smoking

9. I remove things from my home or place of work that remind me of smoking

10. I have someone who listens when I need to talk about my smoking

11. I think about information from articles and ads on how to stop smoking

12. I consider the view that smoking can be harmful to the environment

13. I tell myself that if 1 try hard enough 1 can keep from smoking.

14. I find society changing in ways that make it easier for nonsmokers

15. My need for cigarettes makes me feel disappointed in myself

16. I have someone I can count on when I'm having problems with smoking

17. I do something else instead of smoking when I need to relax

18. I react emotionally to wamings about smoking cigarettes

19. I keep things around my home or place of work that remind me not to smoke...

20. I am rewarded by others if I don't smoke

21. I stop to think about my doctor telling me to quit smoking

22. I do things my doctor recommended to avoid smoking

\begin{tabular}{|c|c|c|c|c|}
\hline (1) & (2) & (2) & (1) & (3) \\
\hline & (2) & (0) & () & 0 \\
\hline (1) & (2) & (2) & (a) & (0) \\
\hline (1) & (2) & (2) & (1) & (1) \\
\hline & (2) & (2) & () & (1) \\
\hline (1) & (2) & (อ) & (๑) & (3) \\
\hline (1) & (2) & (3) & (ㄷ) & (3) \\
\hline (1) & (2) & (2) & (1) & (1) \\
\hline (1) & (2) & (2) & () & (ㄱ) \\
\hline D) & (2) & (2) & () & (1) \\
\hline (1) & (2) & (2) & (๑) & () \\
\hline (1) & (2) & (3) & $\odot$ & (3) \\
\hline (1) & (2) & (2) & 0 & (3) \\
\hline & (2) & (3) & (1) & (1) \\
\hline (1) & (2) & (3) & (1) & (1) \\
\hline (1) & (2) & 0 & ( ) & (3) \\
\hline (1) & (2) & (1) & ( ) & (5) \\
\hline (1) & (2) & (3) & (1) & (3) \\
\hline 0 & (2) & (0) & (4) & (3) \\
\hline ๑ & (2) & (9) & (1) & (3) \\
\hline (1) & (2) & (3) & 0 & (c) \\
\hline (8) & (2) & (3) & 0 & (3) \\
\hline
\end{tabular}


Table 1

Characteristics of the Baseline Sample

\begin{tabular}{||c|c|}
\hline Variable & Sample \\
\hline STAGE & \\
Precontemplation & $1745(42.19 \%)$ \\
Contemplation & $1668(40.3 \%)$ \\
Preparation & $731(17.6 \%)$ \\
\hline Age $\quad$ \\
Mean & 40.7 \\
\hline Gender & \\
Males & $1835(44.3 \%)$ \\
Females & $2309(55.7 \%)$ \\
\hline Education & \\
Mean & 12.7 \\
Median and Mode & 12 \\
\hline Employed & \\
Yes & $2929(70.7 \%)$ \\
No & $1214(29.3 \%)$ \\
\hline Race & \\
White & $3959(95.7 \%)$ \\
Black & $105(02.5 \%)$ \\
Asian & $16(00.4 \%)$ \\
Other & $59(01.4 \%)$ \\
\hline Income & \\
Median & $\$ 30$ to $\$ 40 \mathrm{~K}$ \\
\hline Age Started Smoking & \\
Mean & 16.4 \\
Median and Mode & 16 \\
\hline \hline
\end{tabular}


Table 1 (continued)

Characteristics of the Baseline Sample

\begin{tabular}{||c|c||}
\hline \hline Variable & Sample \\
\hline Cigarettes per day & \\
Mean & 20.6 \\
Median and Mode & 20 \\
\hline Marital Status & \\
Never married & $703(17.0 \%)$ \\
Living with partner & $206(5.0 \%)$ \\
Married and living with spouse & $2216(53.5 \%)$ \\
Widowed & $227(5.5 \%)$ \\
Separated & $135(3.3 \%)$ \\
Divorced & $629(15.2 \%)$ \\
Other & $23(0.6 \%)$ \\
\hline
\end{tabular}


Table 2

Maximum Likelihood Factor Loadings for the 5 Factor Correlated Model

\begin{tabular}{|c|c|c|c|c|}
\hline & Baseline & Baseline & 6 Months & 6 Months \\
\hline Factor Variable & $\begin{array}{l}\text { Factor } \\
\text { Loading }\end{array}$ & $\begin{array}{c}\text { Error } \\
\text { Variance }\end{array}$ & $\begin{array}{l}\text { Factor } \\
\text { Loading }\end{array}$ & $\begin{array}{c}\text { Error } \\
\text { Variance }\end{array}$ \\
\hline $\begin{array}{c}\text { Pros } \\
\text { C1 } \\
\text { C3 } \\
\text { C5 } \\
\end{array}$ & $\begin{array}{l}.642 \\
.502 \\
.607 \\
\end{array}$ & $\begin{array}{l}.767 \\
.865 \\
.776 \\
\end{array}$ & $\begin{array}{l}.694 \\
.594 \\
.645 \\
\end{array}$ & $\begin{array}{l}.720 \\
.805 \\
.764 \\
\end{array}$ \\
\hline $\begin{array}{c}\text { Cons } \\
\text { C2 } \\
\text { C4 } \\
\text { C6 }\end{array}$ & $\begin{array}{l}.630 \\
.459 \\
.615\end{array}$ & $\begin{array}{l}.776 \\
.888 \\
.789\end{array}$ & $\begin{array}{l}.697 \\
.600 \\
.717 \\
\end{array}$ & $\begin{array}{l}.717 \\
.800 \\
.697\end{array}$ \\
\hline $\begin{array}{l}\text { Experiential } \\
\text { Processes } \\
\\
\text { CR (D: 4,11) } \\
\text { DR (D: } \mathbf{7 , 1 8}) \\
\text { ER (D: } \mathbf{6 , 1 2}) \\
\text { SO (D: } \mathbf{3 , 1 4}) \\
\text { SR (D: } 8,15)\end{array}$ & $\begin{array}{l}.677 \\
.734 \\
.601 \\
.376 \\
.782\end{array}$ & $\begin{array}{l}.736 \\
.679 \\
.799 \\
.927 \\
.623\end{array}$ & $\begin{array}{l}.679 \\
.746 \\
.581 \\
.405 \\
.777\end{array}$ & $\begin{array}{l}.734 \\
.666 \\
.814 \\
.914 \\
.629\end{array}$ \\
\hline $\begin{array}{l}\begin{array}{r}\text { Behavioral } \\
\text { Processes }\end{array} \\
\text { CC (D: 1,17) } \\
\text { HR (D: 10,16) } \\
\text { RM (D: 5,20) } \\
\text { SC (D: 9,19) } \\
\text { SL (D: } 2,13)\end{array}$ & $\begin{array}{l}.506 \\
.481 \\
.515 \\
.573 \\
.597\end{array}$ & $\begin{array}{l}.862 \\
.877 \\
.857 \\
.820 \\
.802\end{array}$ & $\begin{array}{l}.579 \\
.462 \\
.475 \\
.615 \\
.628\end{array}$ & $\begin{array}{l}.815 \\
.887 \\
.880 \\
.788 \\
.778\end{array}$ \\
\hline $\begin{array}{l}\text { Habit Strength } \\
\text { Cigsmk } \\
\text { Temptation }\end{array}$ & $\begin{array}{l}.354 \\
.934\end{array}$ & $\begin{array}{l}.935 \\
.357\end{array}$ & $\begin{array}{l}.393 \\
.917\end{array}$ & $\begin{array}{l}.920 \\
.399\end{array}$ \\
\hline
\end{tabular}

Note: Variable labels refer to the Section 5 (A-D) items in the questionnaire. See Appendix $\mathrm{A}$ for the actual items. Cigsmk = number of cigarettes smoked a day. All factor loadings were statistically significant at $p<.001$. 
Table 3

Scale Statistics and Pearson Correlations for the 5 Factor Correlated Measurement Model at Baseline and 6 Months

\section{Baseline}

\begin{tabular}{||c|c|c|c|c|c|c|c|c||}
\hline Scales & Mean & S.D. & Alpha & Pros & Cons & Exp & Beh & HS \\
\hline Pros & 2.45 & 0.95 & .61 & --- & $.167^{*}$ & $.132^{*}$ & .022 & $398^{*}$ \\
Cons & 2.95 & 1.02 & .59 & & & $.594^{*}$ & $.402^{*}$ & .007 \\
Exp & 2.93 & 0.85 & .77 & & & - & $.592^{*}$ & .008 \\
Beh & 2.20 & 0.72 & .67 & & & & ---- & -.150 \\
HS & 25.32 & 7.56 & .50 & & & & & ----- \\
\hline
\end{tabular}

\section{Months}

\begin{tabular}{||c|c|c|c|c|c|c|c|c||}
\hline \hline Scales & Mean & S.D. & Alpha & Pros & Cons & Exp & Beh & HS \\
\hline \hline Pros & 2.44 & 1.00 & .69 & --- & $.202^{*}$ & $.187^{*}$ & $.046^{*}$ & $386^{*}$ \\
Cons & 3.03 & 1.12 & .72 & & --- & $.636^{*}$ & $.417^{*}$ & $.096^{*}$ \\
Exp & 2.87 & 0.83 & .77 & & & --- & $.608^{*}$ & $.060^{*}$ \\
Beh & 2.24 & 0.73 & .69 & & & & ---- & -.151 \\
HS & 25.35 & 10.41 & .53 & & & & & ---- \\
\hline
\end{tabular}

Note: $\underline{N}=4144$ at baseline. $\underline{N}=3394$ at 6 months

Higher means indicate greater importance for the pros and cons scales (possible range $=1$ to 5); greater frequency for the experiential and behavioral processes (possible range $=1$ to 5); greater degree of habit strength (range $=5$ to 68).

Pros = Pros of smoking; Cons $=$ Cons of smoking; Exp = Experiential processes; Beh $=$ Behavioral processes; $\mathrm{HS}=$ Smoking habit strength $* \mathrm{p}<.01$ 
Table 4

Scale Statistics for the Panel Analyses

Baseline

6 Months

\begin{tabular}{|c|c|c|c|c|}
\hline Scales & Mean & S.D. & Mean & S.D. \\
\hline $\begin{array}{c}\text { Total Sample } \\
\text { Pros } \\
\text { Cons } \\
\text { Exp } \\
\text { Beh }\end{array}$ & $\begin{array}{l}2.45 \\
2.95 \\
2.93 \\
2.20\end{array}$ & $\begin{array}{l}0.95 \\
1.02 \\
0.85 \\
0.72\end{array}$ & $\begin{array}{l}2.44 \\
3.03 \\
2.87 \\
2.24\end{array}$ & $\begin{array}{l}1.00 \\
1.12 \\
0.83 \\
0.73\end{array}$ \\
\hline $\begin{array}{c}\text { PC PC } \\
\text { Pros } \\
\text { Cons } \\
\text { Exp } \\
\text { Beh }\end{array}$ & $\begin{array}{l}2.45 \\
2.58 \\
2.50 \\
1.83\end{array}$ & $\begin{array}{l}0.98 \\
0.93 \\
0.72 \\
0.60\end{array}$ & $\begin{array}{l}2.50 \\
2.63 \\
2.46 \\
1.85\end{array}$ & $\begin{array}{l}1.01 \\
1.02 \\
0.69 \\
0.61\end{array}$ \\
\hline $\begin{array}{c}\text { PC } \bullet \mathbf{C} \\
\text { Pros } \\
\text { Cons } \\
\text { Exp } \\
\text { Beh }\end{array}$ & $\begin{array}{l}2.54 \\
2.92 \\
2.80 \\
2.00\end{array}$ & $\begin{array}{l}0.90 \\
0.90 \\
0.77 \\
0.62\end{array}$ & $\begin{array}{l}2.58 \\
3.11 \\
2.98 \\
2.27\end{array}$ & $\begin{array}{l}0.96 \\
1.05 \\
0.77 \\
0.62\end{array}$ \\
\hline $\begin{array}{l}\mathbf{C} \bullet \mathbf{C} \\
\text { Pros } \\
\text { Cons } \\
\text { Exp } \\
\text { Beh } \\
\end{array}$ & $\begin{array}{l}2.46 \\
3.29 \\
3.23 \\
2.39 \\
\end{array}$ & $\begin{array}{l}0.90 \\
0.99 \\
0.77 \\
0.70 \\
\end{array}$ & $\begin{array}{l}2.49 \\
3.39 \\
3.17 \\
2.40 \\
\end{array}$ & $\begin{array}{l}0.95 \\
1.13 \\
0.76 \\
0.65\end{array}$ \\
\hline $\begin{array}{c}\text { C } \bullet \text { PA } \\
\text { Pros } \\
\text { Cons } \\
\text { Exp } \\
\text { Beh }\end{array}$ & $\begin{array}{l}2.45 \\
3.29 \\
3.37 \\
2.52\end{array}$ & $\begin{array}{l}0.95 \\
1.02 \\
0.82 \\
0.72\end{array}$ & $\begin{array}{l}2.40 \\
3.55 \\
3.38 \\
2.64\end{array}$ & $\begin{array}{l}0.95 \\
1.06 \\
0.80 \\
0.68\end{array}$ \\
\hline $\begin{array}{c}\text { PA } \bullet \text { PA } \\
\text { Pros } \\
\text { Cons } \\
\text { Exp } \\
\text { Beh } \\
\end{array}$ & $\begin{array}{l}2.45 \\
3.35 \\
3.38 \\
2.67\end{array}$ & $\begin{array}{l}0.96 \\
1.04 \\
0.81 \\
0.70\end{array}$ & $\begin{array}{l}2.49 \\
3.66 \\
3.36 \\
2.74\end{array}$ & $\begin{array}{l}1.03 \\
1.08 \\
0.77 \\
0.69\end{array}$ \\
\hline $\begin{array}{c}\text { PA A } \\
\text { Pros } \\
\text { Cons } \\
\text { Exp } \\
\text { Beh }\end{array}$ & $\begin{array}{l}2.13 \\
3.32 \\
3.34 \\
2.71\end{array}$ & $\begin{array}{l}0.92 \\
0.97 \\
0.86 \\
0.78\end{array}$ & $\begin{array}{l}1.67 \\
2.82 \\
2.95 \\
2.75\end{array}$ & $\begin{array}{l}0.76 \\
1.25 \\
0.99 \\
0.82\end{array}$ \\
\hline
\end{tabular}




\section{Table 5}

Maximum Likelihood Parameter Estimates

Total Sample $(\mathbf{N}=\mathbf{3 4 6 5})$

\section{Structural Parameters}

\begin{tabular}{||c|c|c||}
\hline Baseline & 6 Months & Parameter Estimates \\
\hline Pros & Pros & $.710^{*}$ \\
Pros & Cons & -.049 \\
Pros & Experiential & .022 \\
Pros & Behavioral & .026 \\
Cons & Pros & $-.233^{*}$ \\
Cons & Cons & .319 \\
Cons & Experiential & .120 \\
Cons & Behavioral & .147 \\
Experiential & Pros & $.379^{*}$ \\
Experiential & Cons & $.655^{*}$ \\
Experiential & Experiential & $.668^{*}$ \\
Experiential & Behavioral & -.043 \\
Behavioral & Pros & $-.195^{*}$ \\
Behavioral & Cons & $-.272^{*}$ \\
Behavioral & Experiential & -.047 \\
Behavioral & Behavioral & $.597^{*}$ \\
\hline
\end{tabular}

\section{Correlational Parameters}

\begin{tabular}{|ll|c|c||}
\hline \hline & & Baseline & 6 Months \\
\hline Pros $\$$ & Cons & $.283^{*}$ & $.354^{*}$ \\
Pros & $.185^{*}$ & $.231^{*}$ \\
Pros & .022 & $.102^{*}$ \\
Cons & Beh & $.878^{*}$ & $.697^{*}$ \\
Cons & $.637^{*}$ & $.505^{*}$ \\
Exp Beh & $.807^{*}$ & $.834^{*}$ \\
\hline
\end{tabular}

Note: Pros = Pros of smoking; Cons = Cons of smoking;

Exp $=$ Experiential processes; $B$ Beh $=$ Behavioral processes

${ }^{*}=p<.05$ 
Table 6

Comparison of 7 Panel Analyses for Stage Subgroups

\begin{tabular}{||c|ccc|c|c|c||}
\hline Scales & $\mathrm{N}$ & $\chi^{2}$ & $\mathrm{df}$ & $\mathrm{RMR}$ & $\mathrm{TLI}$ & $\mathrm{CFI}$ \\
\hline Total Sample & 3465 & 2603 & 420 & .029 & .932 & .942 \\
\hline $\mathbf{P C} \cdot \mathbf{P C}$ & 1031 & 1093 & 420 & .035 & .916 & .928 \\
\hline $\mathbf{P C} \cdot \mathbf{C}$ & 269 & 625 & 344 & .048 & .858 & .879 \\
\hline $\mathbf{C} \cdot \mathbf{C}$ & 685 & 813 & 420 & .034 & .926 & .938 \\
\hline $\mathbf{C} \cdot \mathbf{P A}$ & 203 & 595 & 420 & .048 & .893 & .909 \\
\hline $\mathbf{P A} \cdot \mathbf{P A}$ & 198 & 583 & 420 & .044 & .899 & .915 \\
\hline $\mathbf{P A} \cdot \mathbf{A}$ & 76 & $\mathrm{CC}^{*}$ & $\mathrm{CC}^{*}$ & $\mathrm{CC}^{*}$ & $\mathrm{CC}^{*}$ & $\mathrm{CC}^{*}$ \\
\hline
\end{tabular}

Note: $\mathrm{CC}^{*}=$ Condition Code 
Table 7

Maximum Likelihood Parameter Estimates

Precontemplation - Precontemplation $(\mathrm{N}=1031)$

\section{$\underline{\text { Structural Parameters }}$}

\begin{tabular}{||c|c|c||}
\hline Baseline & 6 Months & Parameter Estimates \\
\hline Pros & Pros & $.771^{*}$ \\
Pros & Cons & -.314 \\
Pros & Experiential & .429 \\
Pros & Behavioral & -.187 \\
Cons & Pros & -.057 \\
Cons & Cons & .480 \\
Cons & Experiential & .415 \\
Cons & Behavioral & -.205 \\
Experiential & Pros & .008 \\
Experiential & Cons & .041 \\
Experiential & Experiential & $.919^{*}$ \\
Experiential & Behavioral & -.213 \\
Behavioral & Pros & -.041 \\
Behavioral & Cons & .699 \\
Behavioral & Experiential & -.846 \\
Behavioral & Behavioral & $.873^{*}$ \\
\hline
\end{tabular}

\section{Correlational Parameters}

\begin{tabular}{|c|c|c|c|}
\hline & & Baseline & 6 Months \\
\hline Pros & - Cons & $.283^{*}$ & $.354^{*}$ \\
\hline Pros & - $\quad \operatorname{Exp}$ & $.185^{*}$ & $.182^{*}$ \\
\hline Pros & - Beh & .022 & $.297^{*}$ \\
\hline Cons & - $\quad \operatorname{Exp}$ & $.878^{*}$ & $.727^{*}$ \\
\hline Cons & - Beh & $.637^{*}$ & $.632^{*}$ \\
\hline Exp & - Beh & $.807^{*}$ & $.983^{*}$ \\
\hline
\end{tabular}

Note: Pros $=$ Pros of smoking; Cons $=$ Cons of smoking;

Exp $=$ Experiential processes; $B$ eh $=$ Behavioral processes

$* p<.05$ 
Table 8

Maximum Likelihood Parameter Estimates

Precontemplation - Contemplation $(N=269)$

\section{$\underline{\text { Structural Parameters }}$}

\begin{tabular}{||c|c|c||}
\hline Baseline & 6 Months & Parameter Estimates \\
\hline Pros & Pros & $.760^{*}$ \\
Pros & Cons & .131 \\
Pros & Experiential & .104 \\
Pros & Behavioral & -.035 \\
Experiential & Pros & .156 \\
Experiential & Cons & $.619^{*}$ \\
Experiential & Experiential & $.655^{*}$ \\
Experiential & Behavioral & .116 \\
Behavioral & Pros & -.004 \\
Behavioral & Cons & .120 \\
Behavioral & Experiential & -.096 \\
Behavioral & Behavioral & $.511^{*}$ \\
\hline
\end{tabular}

\section{Correlational Parameters}

\begin{tabular}{|c|c|c|c|}
\hline & & Baseline & 6 Months \\
\hline Pros & - Cons & -------. & .156 \\
\hline Pros & - $\quad \operatorname{Exp}$ & $.207^{*}$ & .179 \\
\hline Pros & - Beh & . 156 & .021 \\
\hline Cons & - $\quad \operatorname{Exp}$ & -_-_..... & $.720^{*}$ \\
\hline Cons & - Beh & --------- & $.521^{*}$ \\
\hline Exp & - Beh & $.608^{*}$ & $.976^{*}$ \\
\hline
\end{tabular}

Note: Pros $=$ Pros of smoking; Cons $=$ Cons of smoking;

Exp $=$ Experiential processes; Beh $=$ Behavioral processes

${ }^{*}=\mathrm{p}<.05$ 
Table 9

Maximum Likelihood Parameter Estimates

Contemplation - Contemplation $(\mathbf{N}=\mathbf{6 8 5})$

\section{Structural Parameters}

\begin{tabular}{||c|c|c||}
\hline Baseline & 6 Months & Parameter Estimates \\
\hline Pros & Pros & $.635^{*}$ \\
Pros & Cons & .042 \\
Pros & Experiential & .154 \\
Pros & Behavioral & -.147 \\
Cons & Pros & -.074 \\
Cons & Cons & .169 \\
Cons & Experiential & $.699^{*}$ \\
Cons & Behavioral & $-.254^{*}$ \\
Experiential & Pros & .098 \\
Experiential & Cons & .063 \\
Experiential & Experiential & $.670^{*}$ \\
Experiential & Behavioral & -.042 \\
Behavioral & Pros & .094 \\
Behavioral & Cons & .002 \\
Behavioral & Experiential & .117 \\
Behavioral & Behavioral & $.584^{*}$ \\
\hline
\end{tabular}

\section{Correlational Parameters}

\begin{tabular}{|c|c|c|c|}
\hline & & Baseline & 6 Months \\
\hline Pros & - Cons & $.352^{*}$ & $.298^{*}$ \\
\hline Pros & - $\quad \operatorname{Exp}$ & $.317^{*}$ & $.163^{*}$ \\
\hline Pros & - Beh & .073 & .106 \\
\hline Cons & - $\quad \operatorname{Exp}$ & $.768^{*}$ & $.653^{*}$ \\
\hline Cons & - Beh & $.462^{*}$ & $.453^{*}$ \\
\hline Exp & - Beh & $.716^{*}$ & $.769^{*}$ \\
\hline
\end{tabular}

Note: Pros $=$ Pros of smoking; Cons $=$ Cons of smoking;

Exp $=$ Experiential processes; Beh $=$ Behavioral processes

${ }^{*}=\mathrm{p}<.05$ 
Table 10

Maximum Likelihood Parameter Estimates

Contemplation - Preparation $(\mathrm{N}=203)$

\section{$\underline{\text { Structural Parameters }}$}

\begin{tabular}{|c|c|c||}
\hline Baseline & 6 Months & Parameter Estimates \\
\hline Pros & Pros & $.598^{*}$ \\
Pros & Cons & -.077 \\
Pros & Experiential & .059 \\
Pros & Behavioral & .018 \\
Cons & Pros & -.873 \\
Cons & Cons & .431 \\
Cons & Experiential & .128 \\
Cons & Behavioral & .511 \\
Experiential & Pros & $1.235^{*}$ \\
Experiential & Cons & .521 \\
Experiential & Experiential & .532 \\
Experiential & Behavioral & -.333 \\
Behavioral & Pros & $-.525^{*}$ \\
Behavioral & Cons & -.319 \\
Behavioral & Experiential & .024 \\
Behavioral & Behavioral & $.474^{*}$ \\
\hline
\end{tabular}

\section{Correlational Parameters}

\begin{tabular}{|c|c|c|c|}
\hline & & Baseline & 6 Months \\
\hline Pros & Cons & .152 & -.054 \\
\hline Pros & Exp & .080 & .148 \\
\hline Pros & Beh & -.026 & .129 \\
\hline Cons & - $\quad \operatorname{Exp}$ & $.841^{*}$ & $.618^{*}$ \\
\hline Cons & - Beh & $.555^{*}$ & $.423^{*}$ \\
\hline Exp & - Beh & $.717^{*}$ & $.839^{*}$ \\
\hline
\end{tabular}

Note: $\quad$ Pros $=$ Pros of smoking; Cons $=$ Cons of smoking;

Exp $=$ Experiential processes; Beh $=$ Behavioral processes

$* \mathrm{p}<.05$ 
Table 11

Maximum Likelihood Parameter Estimates

Preparation - Preparation $(\mathbf{N}=198)$

\section{Structural Parameters}

\begin{tabular}{||c|c|c||}
\hline \hline Baseline & 6 Months & Parameter Estimates \\
\hline Pros & Pros & $.586^{*}$ \\
Pros & Cons & -.033 \\
Pros & Experiential & -.287 \\
Pros & Behavioral & -.350 \\
Cons & Pros & .024 \\
Cons & Cons & .281 \\
Cons & Experiential & .932 \\
Cons & Behavioral & 1.213 \\
Experiential & Pros & .213 \\
Experiential & Cons & .904 \\
Experiential & Experiential & -.030 \\
Experiential & Behavioral & -.667 \\
Behavioral & Pros & -.167 \\
Behavioral & Cons & -.562 \\
Behavioral & Experiential & .008 \\
Behavioral & Behavioral & .104 \\
\hline
\end{tabular}

\section{Correlational Parameters}

\begin{tabular}{||ll|c|c||}
\hline \hline & & Baseline & 6 Months \\
\hline Pros & Cons & $.485^{*}$ & -.009 \\
Pros & Exp & $.306^{*}$ & .166 \\
Pros & .235 & .047 \\
Cons & Exp & $.850^{*}$ & $.544^{*}$ \\
Cons & Beh & $.681^{*}$ & $.699^{*}$ \\
Exp - Beh & $.815^{*}$ & $.923^{*}$ \\
\hline
\end{tabular}

Note: Pros $=$ Pros of smoking; Cons $=$ Cons of smoking;

Exp $=$ Experiential processes; Beh $=$ Behavioral processes

$* \mathrm{p}<.05$ 
Table 12

Comparison of 7 Prediction Models' Paths to Habit Strength (HS) for Stage Subgroups

\begin{tabular}{|c|c|c|c|c|}
\hline Pred. Analyses & Pros & Cons & Exp & Beh \\
\hline $\begin{array}{c}\text { Total Sample } \\
\text { HS }\end{array}$ & $.477^{*}$ & $-.329^{*}$ & $.721^{*}$ & $-.450^{*}$ \\
\hline $\begin{array}{c}\text { PC }>\text { PC } \\
\text { HS }\end{array}$ & $.570^{*}$ & -.650 & 1.149 & $-.595^{*}$ \\
\hline $\begin{array}{c}\mathrm{PC} \rightarrow \mathrm{C} \\
\mathrm{HS}\end{array}$ & $\mathrm{CC}^{* *}$ & $\mathrm{CC}^{* *}$ & $\mathrm{CC}^{* *}$ & $\mathrm{CC}^{* *}$ \\
\hline $\begin{array}{c}\mathrm{C} \bullet \mathrm{C} \\
\mathrm{HS}\end{array}$ & $.424^{*}$ & -.126 & $.557^{*}$ & $-.492^{*}$ \\
\hline $\begin{array}{c}\mathbf{C} \mapsto \mathbf{P A} \\
\mathbf{H S}\end{array}$ & $.417^{*}$ & -.261 & .779 & $-.554^{*}$ \\
\hline $\begin{array}{c}\mathbf{P A} \mapsto \mathbf{P A} \\
\quad \text { HS }\end{array}$ & $.704^{*}$ & -.734 & 1.468 & -.860 \\
\hline $\begin{array}{c}\text { PA } ・ \text { A } \\
\text { HS }\end{array}$ & $\mathrm{CC}^{* *}$ & $\mathrm{CC}^{* *}$ & $\mathrm{CC}^{* *}$ & $\mathrm{CC}^{* *}$ \\
\hline
\end{tabular}

Note: $\mathrm{PC}=$ precontemplation $; \mathrm{C}=$ contemplation; $\mathrm{PA}=$ preparation; $\mathrm{A}=$ Action ${ }^{*}$ Significance $<.05 ;{ }^{* *}$ Condition Code 
Table 13

Comparison of 7 Predictor Analyses for Stage Subgroups

\begin{tabular}{|c|c|c|c|c|c|c|c|}
\hline Scales & $\mathrm{N}$ & $\chi^{2}$ & $\mathrm{df}$ & RMR & TLI & CFI & $\mathrm{R}^{2}$ \\
\hline Total Sample & 3465 & 1292 & 125 & .032 & .897 & .916 & .33 \\
\hline $\mathbf{P C} \bullet \mathbf{P C}$ & 1031 & 449 & 125 & .034 & .879 & .901 & .46 \\
\hline $\mathrm{PC} \cdot \mathrm{C}$ & 269 & $\mathrm{CC}^{*}$ & $\mathrm{CC}^{*}$ & $\mathrm{CC}^{*}$ & $\mathrm{CC}^{*}$ & $\mathrm{CC}^{*}$ & $\mathrm{CC}^{*}$ \\
\hline 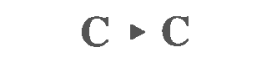 & 685 & 382 & 125 & .037 & .858 & .884 & .39 \\
\hline $\mathbf{C} \rightarrow \mathbf{P A}$ & 203 & 202 & 125 & .049 & .865 & .889 & .38 \\
\hline $\mathbf{P A} \bullet \mathbf{P A}$ & 198 & 202 & 125 & .050 & .861 & .887 & .67 \\
\hline $\mathbf{P A} \rightarrow \mathbf{A}$ & 76 & $\mathrm{CC}^{*}$ & $\mathrm{CC}^{*}$ & $\mathrm{CC}^{*}$ & $\mathrm{CC}^{*}$ & $\mathrm{CC}^{*}$ & $\mathrm{CC}^{*}$ \\
\hline
\end{tabular}

Note: ${ }^{*}$ Condition Code 
Figure 1 . Heuristic Model $\mathbb{A}$ : experiential and behavioral processes as independent variables at baseline predicting the pros and cons of smoking at 6 months. 
$\frac{0}{2}$

4
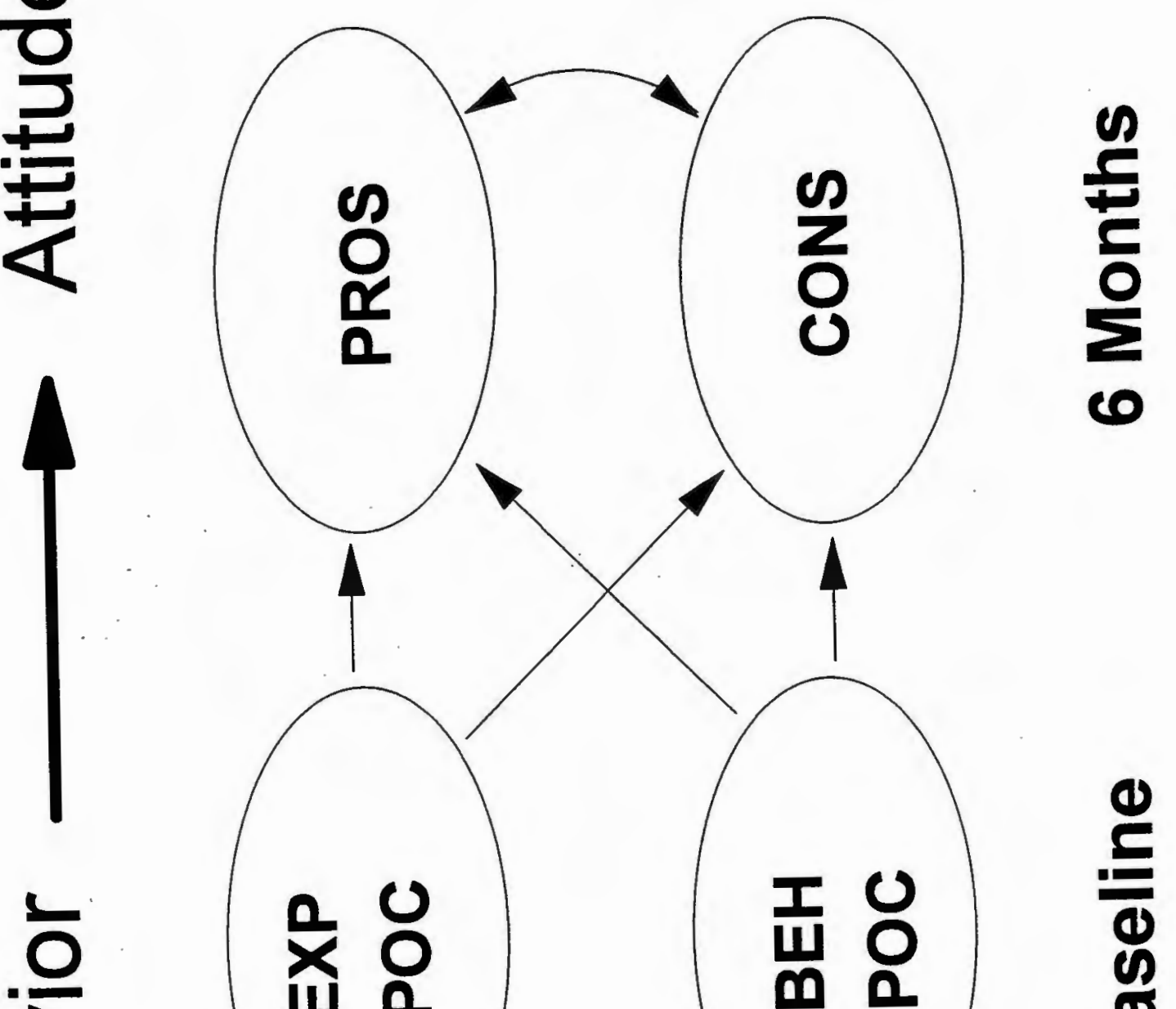

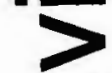

(

$\frac{1}{1}$

$m$ 
Figure 2. Heuristic Model B: pros and cons of smoking as independent variables at baseline predicting the experiential and behavioral processes at 6 months. 

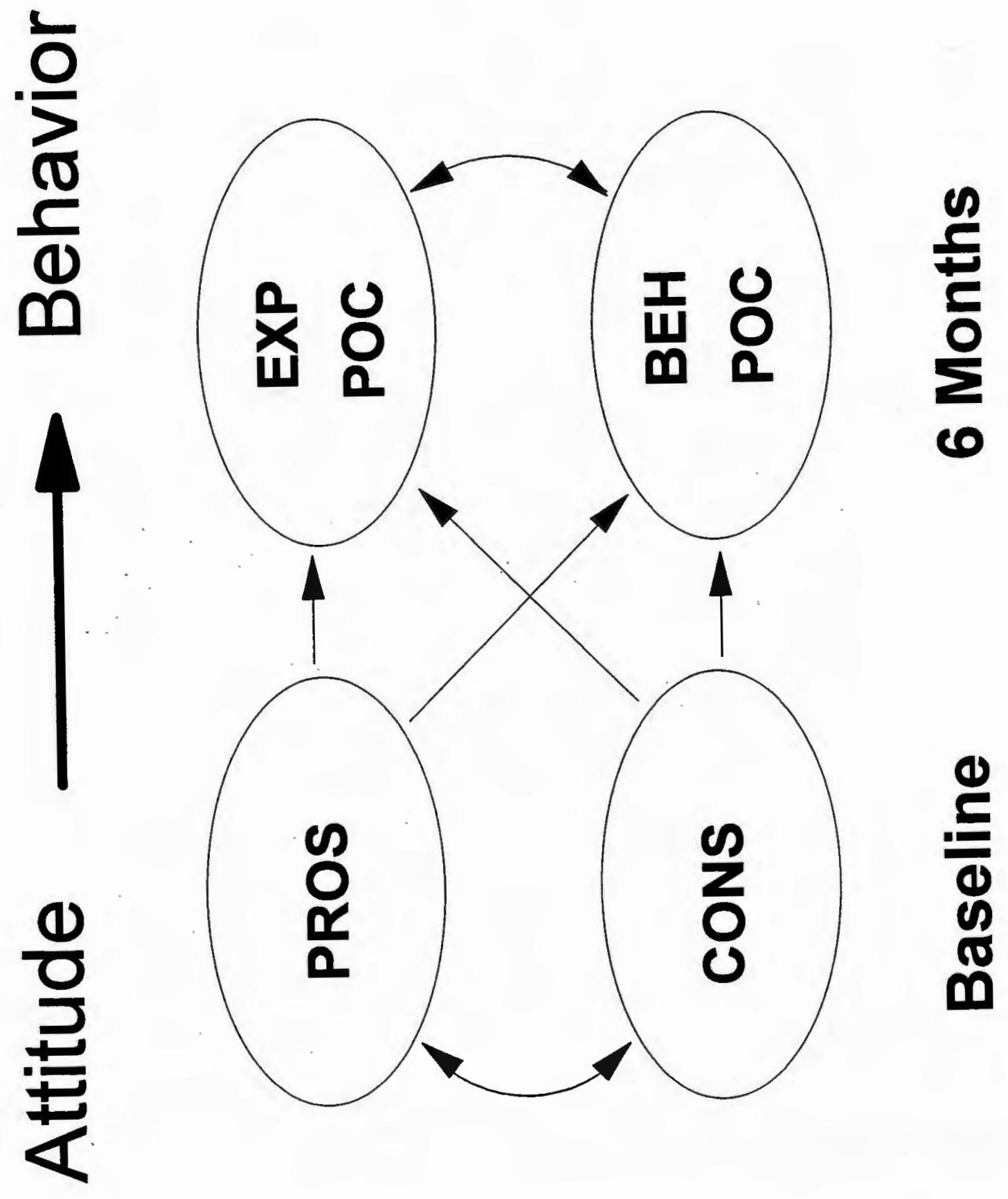
Figure 3. Longitudinal panel analysis model for the total sample $(\underline{\mathbb{N}}=3,465)$. 


\section{Total Sample}

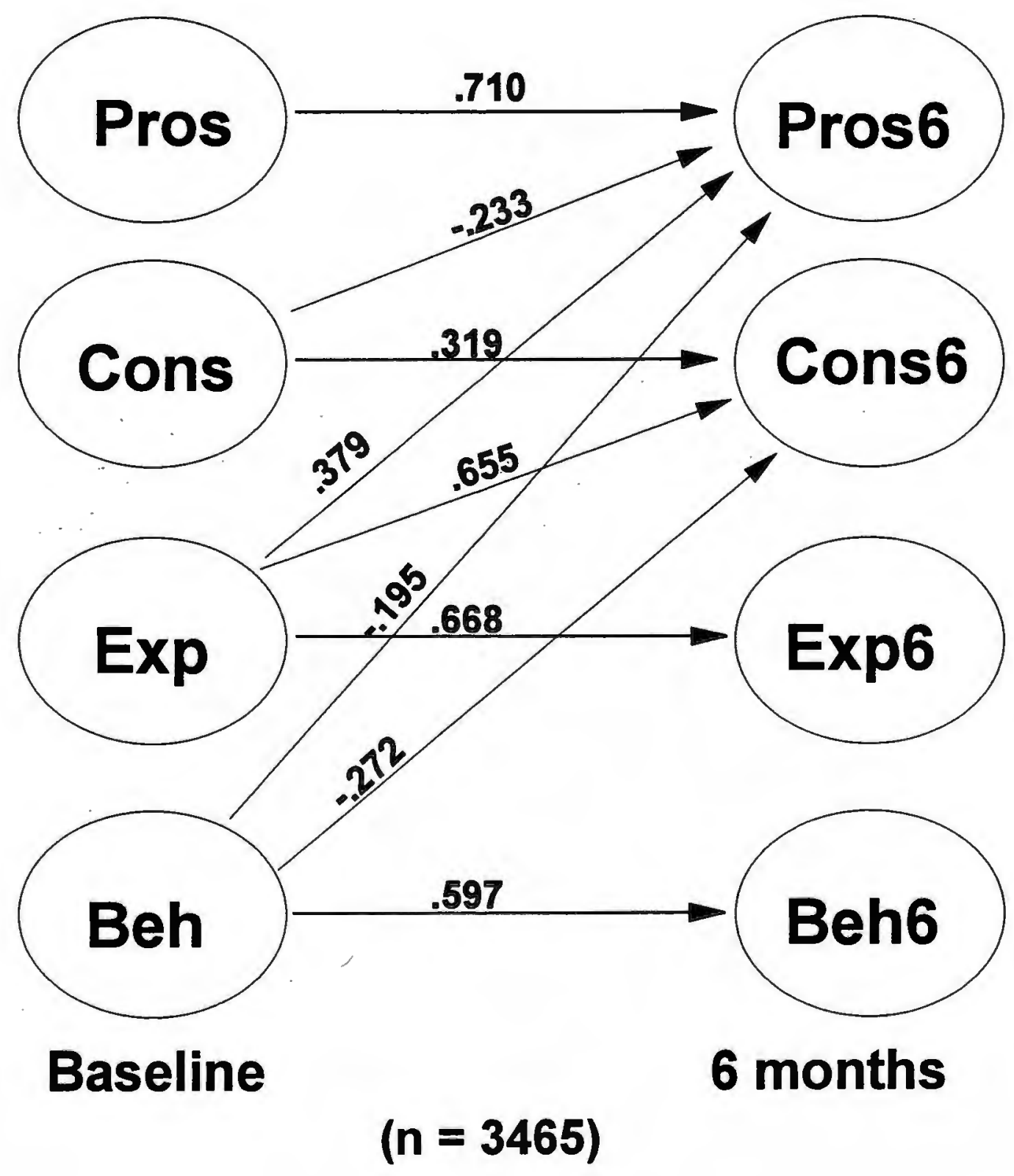


Figure 4. Longitudinal panel analysis model for the precontemplation->precontemplation staging subgroup $(\underline{N}=1,031)$. 


\section{Precontemplation $\rightarrow$ Precontemplation}
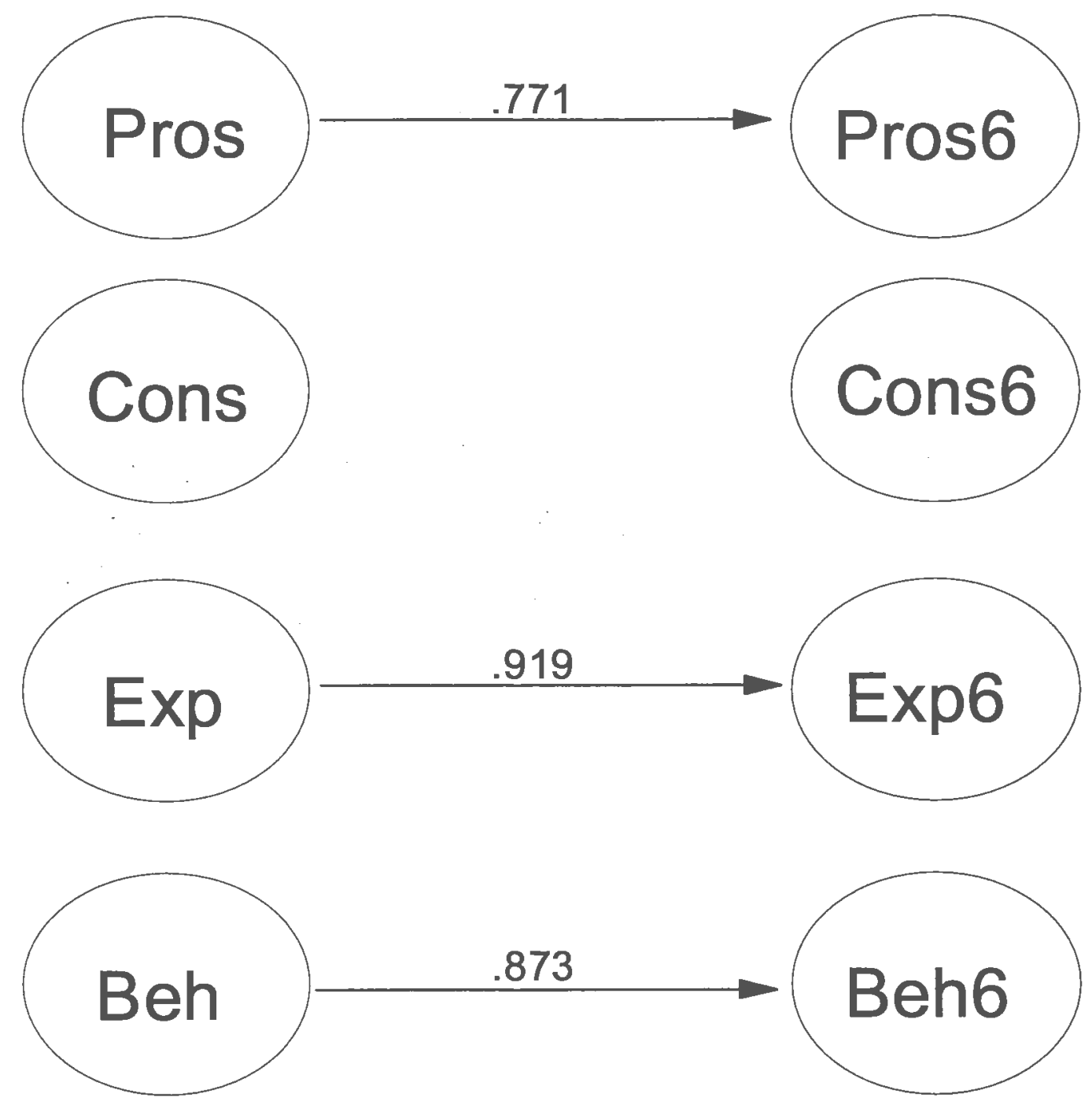

Baseline

6 months

$$
(n=1031)
$$


Figure 5. Longitudinal panel analysis model for the precontemplation->contemplation staging subgroup ( $\underline{\mathrm{N}}$ $=269)$. 


\section{Precontemplation $\rightarrow$ Contemplation}
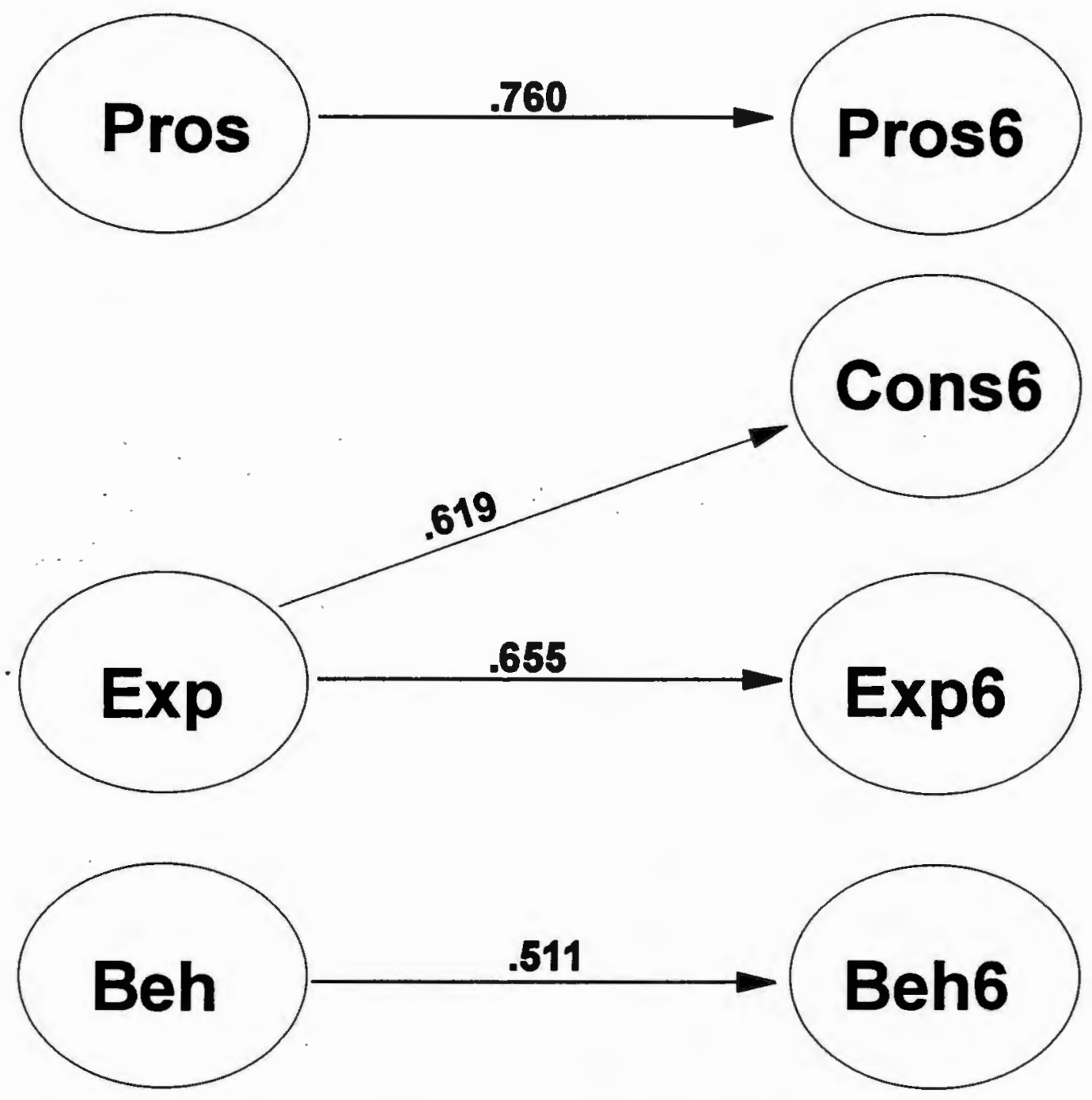

Baseline

6 months

$$
\text { ( } n=269)
$$


Figure 6. Longitudinal panel analysis model for the contemplation->contemplation staging $\operatorname{subgroup}(\underline{\mathrm{N}}=$ 685) . 


\section{Contemplation $\rightarrow$ Contemplation}
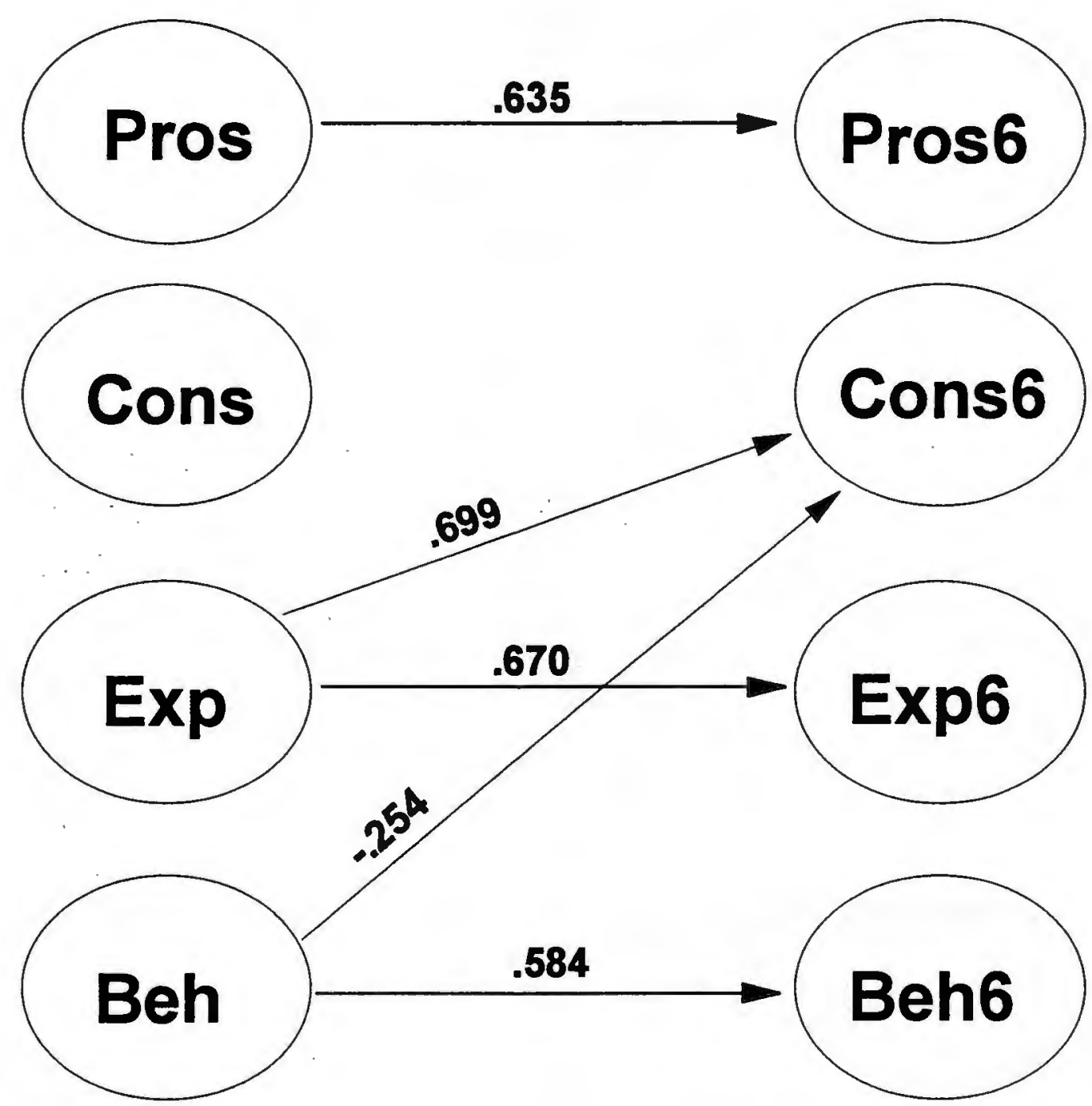

Baseline

6 months

$(n=685)$ 
Fiqure 7. Longitudinal panel analysis model for the contemplation->preparation staging subgroup $\langle\underline{N}=$ 203). 


\section{Contemplation $\rightarrow$ Preparation}

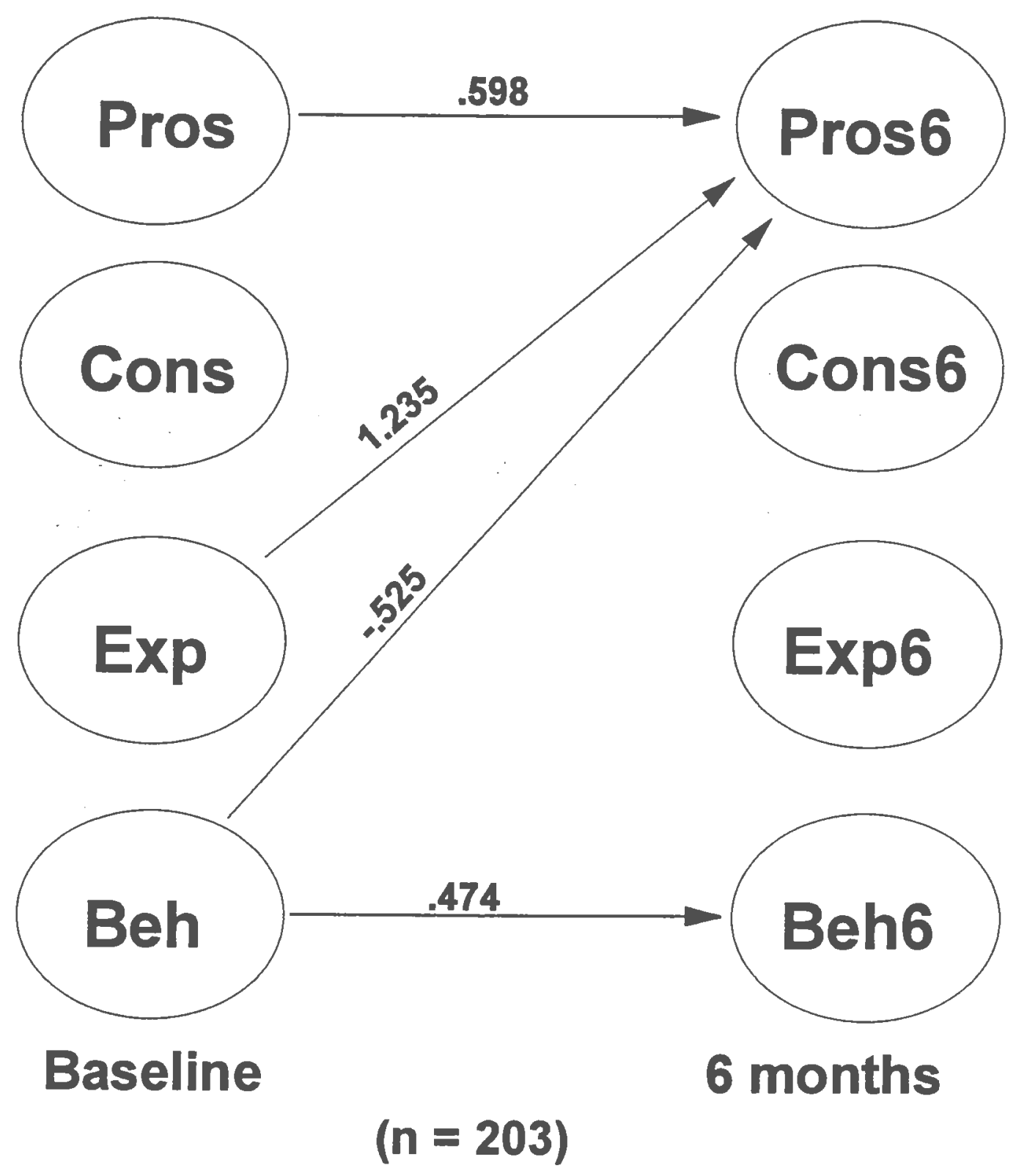


Figure 8. Longitudinal panel analysis model for the preparation->preparation staging subgroup $(\underline{\mathbb{N}}=$ 198). 


\section{Preparation $\rightarrow$ Preparation}
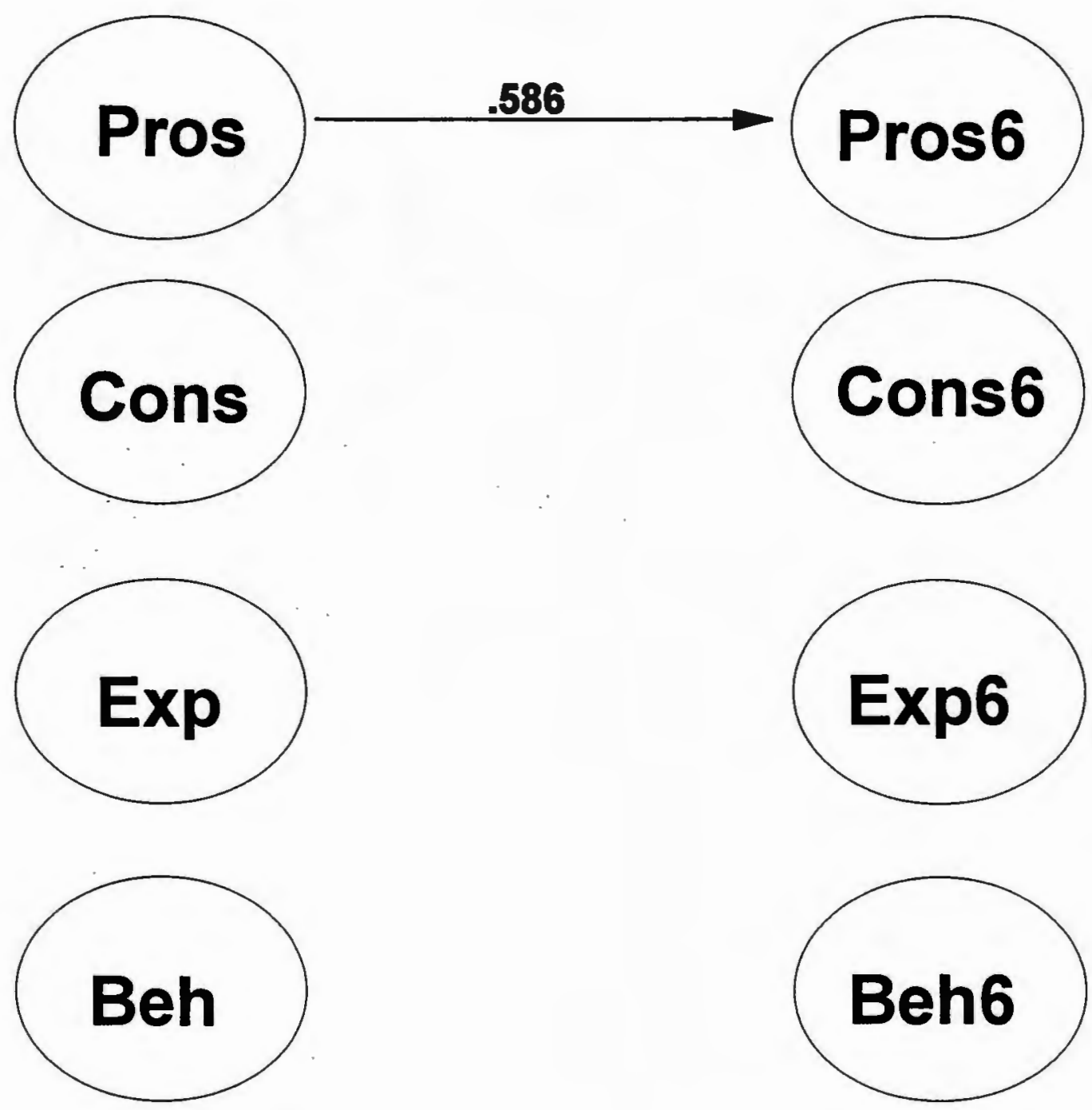

Baseline

6 months

( $n=198)$ 
Figure 9. Longitudinal prediction model for the pros and cons of smoking and the experiential and behavioral processes of change as independent variables predicting habit strength. 


\section{Prediction Model}

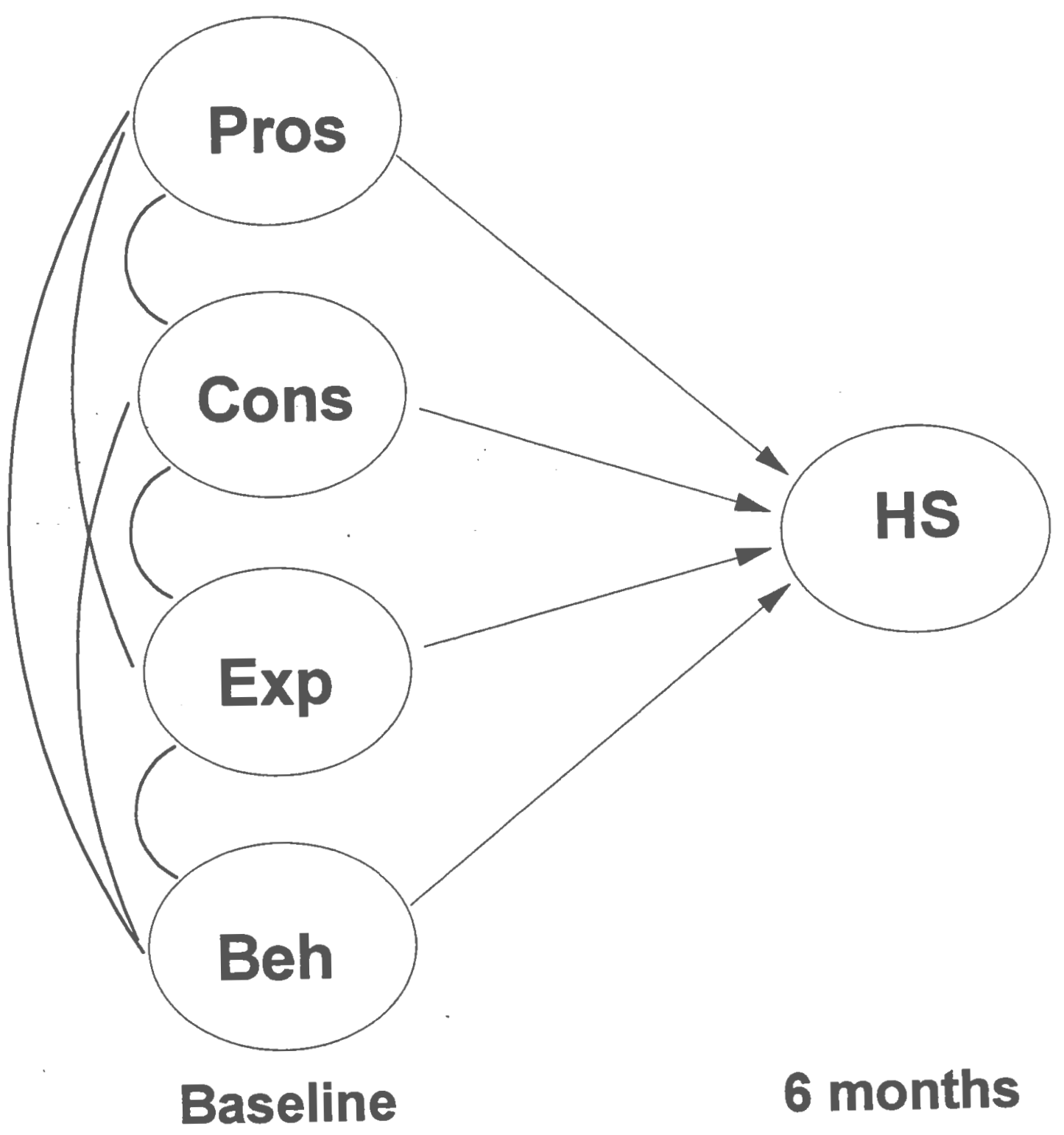


Figure 10. Longitudinal panel analysis for the total sample of female smokers $(\underline{\mathrm{N}}=1,947)$. 
Females
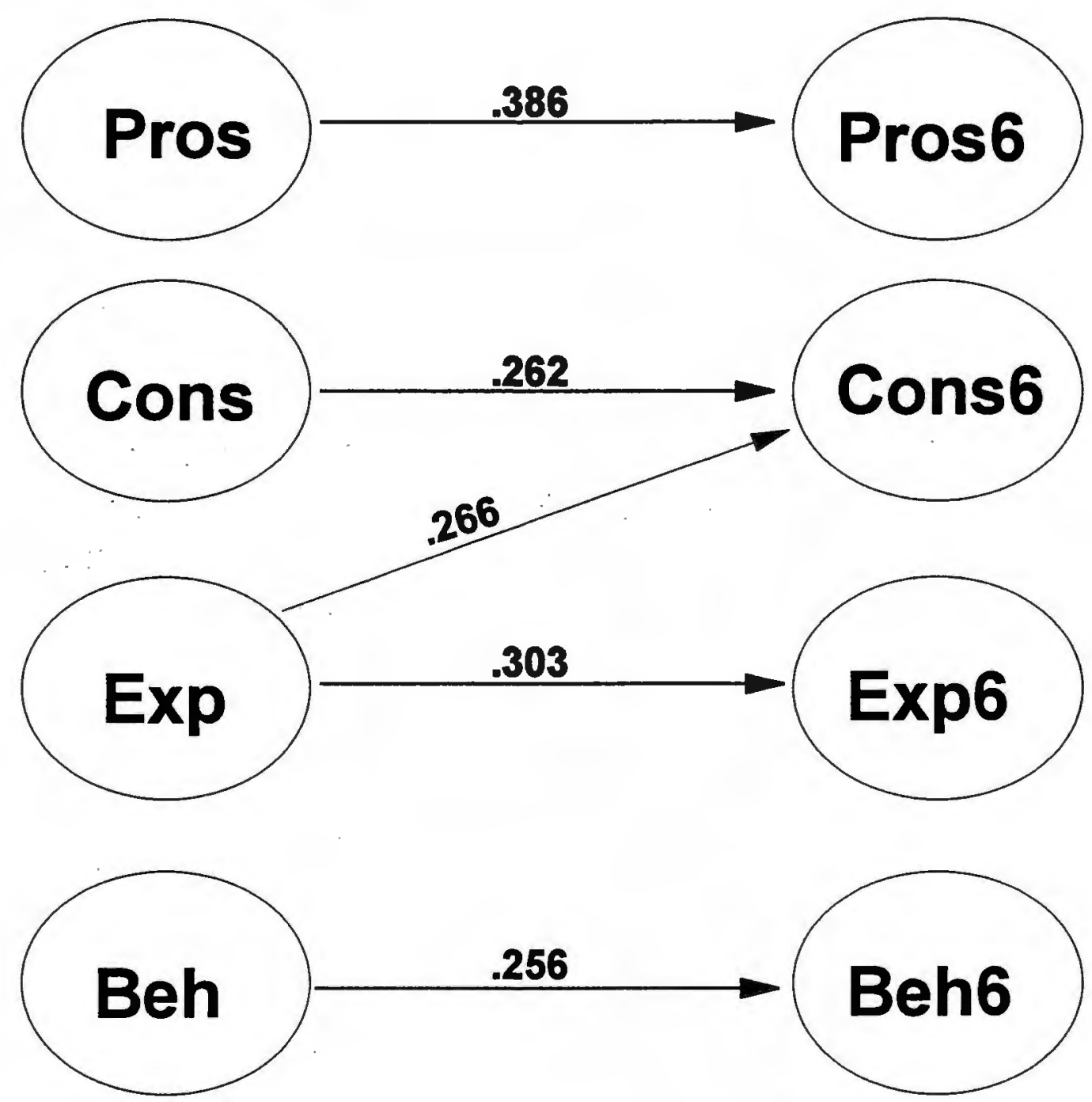

Baseline

6 months

( $n=1947)$ 
Figure 11. Longitudinal panel analysis for the total sample of male smokers $(\underline{\mathrm{N}}=1,548)$. 


\section{Males}

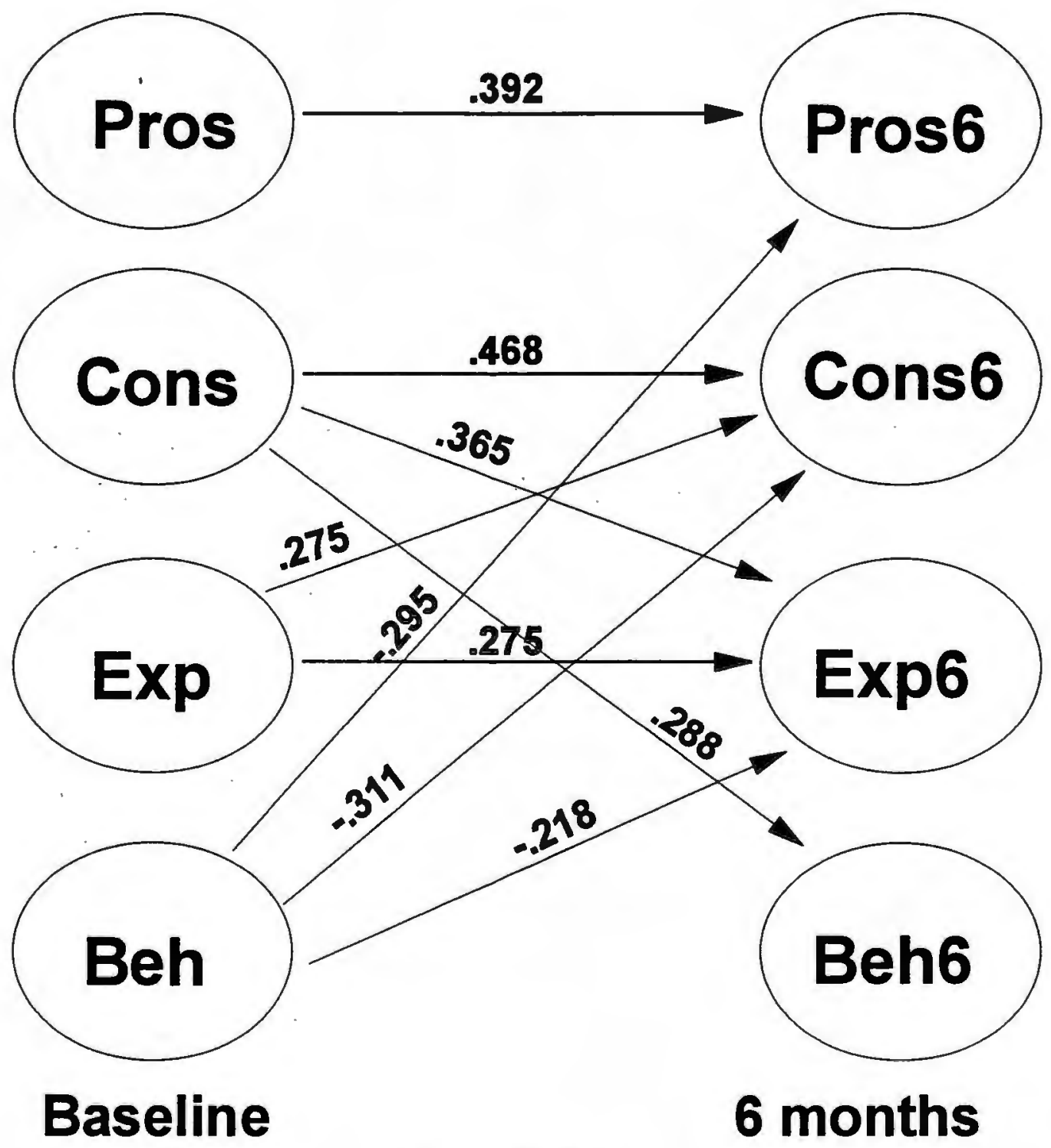

( $n=1548)$ 


\section{Bibliography}

Abrams, D.B., Follick, M.J., \& Beiner L. (1988, November). Individual versus group self-help smoking cessation at the workplace: Initial impact and 12 -month outcomes. In T. Glynn (Chair), Four National Cancer Institute-funded self-help smoking cessation trials: Interim results and emerging patterns. Symposium presented at the annual meeting of the Association for the Advancement of Behavior therapy, New York.

Bandura, A. (1977). Self-efficacy: Toward a unifying theory of behavior change. Psychological Review, 84, 191-215.

Bandura, A. (1982). Self-efficacy mechanism in human agency. American Psychologist, 37, 122-147.

Baer, J.S., Holt, C.S., \& Lichtenstein, E. (1986). Selfefficacy and smoking re-examined: Construct validity and clinical utility. Journal of Consulting and Clinical Psychology, 54, 846-852. 
Bellis, J., Rossi, J.S., Prochaska, J.O. (1990, August). Structural invariance of the processes of change. Paper presented at the 98th Annual Meeting of the American Psychological Association, Boston, Massachusetts.

Bentler, P.M. (1989). EOS: Structural equation program manual. Los Angeles, CA: BMDP Statistical Software.

Bentler, P.M. (1990). Comparative fit indexes in structural models. Psychological Bulletin, 107, 238-246.

Blais, L.M. (1991). Development of a stages of change model for sun exposure. Unpublished masters thesis, University of Rhode Island, Kingston, R.I.

Boomsma, A. (1983). On the robustness of LISREL (maximum likelihood estimation) against small size and nonnormality: Amsterdam: Sociometric Research Foundation.

Brownell, K.D., Marlatt, G.A., Lichtenstein, E., and Wilson G.T. (1986). Understanding and preventing relapse. American Psychologist, $\underline{44}, 1355-1365$. 
Campbell, M.K., DeVellis, B.M., Strecher, V.J., Ammerman, A.S., DeVellis, R.F., \& Sandler, R.S. (in press). The impact of message tailoring on dietary behavior change for disease prevention in primary care settings. American Journal of Public Health.

Centers for Disease Control. (1991). Smoking attributable mortality and years of potential life lost - United States, 1988. MMWR, 40, $62-71$.

Cliff, N. (1983). Some cautions concerning the application of cáusal modeling methods. Multivariate Behavioral Research, 18, 115-126.

Coelho, R.J. (1984). Self-efficacy and the cessation of smoking. Psychological Reports, 54, 309-310.

Cohen, S.; Lichtenstein, E.; Prochaska, J.O.; Rossi, J.S.; Gritz, E.R.; Carr, C.R..; Orleans, C.T.; Schoenbach, V.J.; Biener, L.; Abrams, D.; DiClemente, C.; Curry, S. ; Marlatt, G.A.; Cummings, K.M.; Emont, S.; Giovino, G.; and Ossip-Klein, D. (1989). Debunking myths about selfquitting. American Psychologist, 44, 1355-1365. 
Condiotte, M.M. \& Lichtenstein, E. (1981). Self-efficacy and relapse in smoking cessation programs. Journal of Clinical and Consulting Psychology, 49, 648-658

Cummings, K.M., Becker, M.H., \& Maille, M.C. (1980). Bringing the models together: An empirical approach to combining variables used to explain health actions. Journal of Behavioral Medicine, 3 , 123-145.

Cronbach, L.J. (1951). Coefficient alpha and the internal structure of tests. Psychometrika, 16, 297-334.

DiClemente, C.C., (1981). Self-efficacy and smoking cessation maintenance: A preliminary report. Cognitive Therapy and Research， $\underline{5}, 175-187$.

DiClemente, C.C., (1986). Self-efficacy and the addictive behaviors. Journal of Social and Clinical Psychology, $\underline{4}$ $302-315$.

DiClemente, C.C., \& Hughes, S.O. (1990). Stages of change profiles in outpatient alcoholism treatment. Journal of Substance Abuse, 2 , 217-235. 
Diclemente, C.C., Prochaska, J.O. (1982). Self change and therapy change of smoking behavior: A comparison of processes of change and maintenance. Addictive Behaviors, 7. $133-142$.

DiClemente, C.C., Prochaska, J.O., Fairhurst, S.K., Velicer, W.F., Velasquez, M.M., \& Rossi, J.S. (1991). The process of smoking cessation: An analysis of precontemplation, contemplation and preparation stages of change. Journal of Consulting and Clinical Psychology, 59, 295-304.

DiClemente, C.C., Prochaska; J.O., \& Gibertini, M. (1985). Self-efficacy and the stages of self-change of smoking. Cognitive Therapy and Research, 9, 181-200.

Fava, J.L., Rossi, J.R., Velicer, W.F., \& Prochaska, J.O. (1991, August). Structural confirmation of short form instruments for the Transtheoretical Model. Paper presented at the 99 th Annual Meeting of the American Psychological Association, San Francisco, California.

Fiore, M., Novotny, T., Manlan, D., Davis, R. (1988). Smoking cessation: Data from the 1986 Adult Use of Tobacco Survey, In Smoking and Health 1987, Proceedings of the 6th World Conference on Smoking and Health, Tokyo, 
November 9-12, 1987. New York, Excerpta Medical, 189-194.

Fiore-Lerner, C. (1990). The Transtheoretical Model of change: Self-change in adolescent delinquent behaviors. Unpublished doctoral dissertation, University of Rhode Island, Kingston, R.I.

Fitzgerald, T.E., Rossi, J.S., \& Prochaska, J.O. (1989, August). Static and process models of self-change of smoking behavior. Paper presented at the 97th annual meeting of the American Psychological Association, New Orleans, LA.

Glynn, T.J, Boyd, G.M., \& Gruman, J.C. (1990). Essential elements of self-help/minimal intervention strategies for smoking cessation. Health Education Quarterly, 17, 329 345 .

Gottlieb, N.H., Galavotti, C., MCCuan, R.S., \& MCAlister, A.L. (1990). Specification of a social cognitive model predicting smoking cessation in a Mexican-American population: A prospective study. Cognitive Therapy and Research, 14, 529-542. 
Janis, I.L., \& Mann, L. (1977). Decision making: A Psychological analysis of conflict, choice and commitment. New York: The Free Press.

Jöreskog, K.G., \& Sörbom, D. (1989). LISREL 7 user's guide. Mooresville, IN: Scientific Software.

Marcus, B.H., Rakowski, W., \& Rossi, J.S. (1992). Assessing motivational readiness and decision-making for exercise. Health Psychology, 11, 257-261.

Marsh, H.W., Balla, J.R., \& McDonald, R.P. (1988). Goodnessof-fit indexes in confirmatory factor analysis: The effect of sample size. Psychological Bulletin, 103, 391 410 .

McConnaughy, E.A., DiClemente, C.C., Prochaska, J.O., \& Velicer, W.F. (1989). Stages of change in psychotherapy: A follow-up report. Psychotherapy, 26, 494-503.

McConnaughy, E.A., Prochaska, J.O., \& Velicer, W.F. (1983). Stages of change in psychotherapy: Measurement and sample profiles. Psychotherapy: Theory, Research and Practice, $\underline{20}, 368-375$. 
McIntyre, K., Lichtenstein, E., Mermelstein, R. (1983): Selfefficacy and relapse in smoking cessation: A replication and extension. Journal of Consulting and Clinical Psychology, 51, 632-633.

O'Connell, D.O., \& Velicer, W.F. (1988). A decisional balance measure and the stages of change model for weight loss. International Journal of the Addictions, 23, $729-$ 750 .

Ockene, J., Kristeller, J.L., Goldberg, R., Ockene, I., Merriam, P., Barrett, S. (1992). Smoking cessation and severity of disease: The coronary artery smoking intervention study. Health Psychology, 11, 119-126.

Orleans, C.T., Schoenback, V.J., Salmon, M.A., Wagner, E.A., Pearson, D.C., Fiedler, J., Quade, D., Porter, C.Q., \& Kaplan, B.A. (1988, November). Effectiveness of self-help quit smoking strategies. In T. Glynn (Chair), Four National Cancer Institute-funded self-help smoking cessation trials: Interim results and emerging patterns. Symposium presented at the annual meeting of the Association for the Advancement of Behavior therapy, New York. 
Pallonen, U.E., Fava, J.L., Salonen, J.T., \& Prochaska, J.O. (1992). Readiness for smoking change among middle-aged Finnish men. Addictive Behaviors, 17, 415-423.

Penney, D. (1988). A comparison of psychotherapy-changers and self-changers in a naturalistic environment. Unpublished doctoral dissertation, University of Rhode Island, Kingston, R.I.

Prochaska, J.O. (1979). Systems of psychotherapy: A transtheoretical analysis. Homewood, IL: Dorsey Press.

Prochaska, J.o (1992). A transtheoretical model of behavior change: Learning from mistakes with majority populations. In D. Becker, D.R. Hill, J.S. Jackson, D.M. Levine, F.A. Stillman, \& S.M. Weiss (Eds.), Health behavior research in minority populations: Access, design, and implementation (pp. 105-111). Bethesda, MD: National Institutes of Health.

Prochaska, J.O., \& DiClemente, C.C. (1982). Transtheoretical therapy: Toward a more integrative model of change. Psychotherapy: Theory, Research and Practice, 19, 276 288 . 
Prochaska, J.O., \& DiClemente, C.C. (1983). Stages and processes of self-change of smoking: Toward an integrative model of change. Journal of Consulting and Clinical Psychology, 51, 390-395.

Prochaska, J.O., \& DiClemente, C.C. (1985). Common processes of change in smoking, weight control, and psychological distress. In S. Shiffman \& T. Wills (Eds.), Coping and substance abuse (pp.345-363). San Diego, CA: Academic Press.

Prochaska, J.O., \& DiClemente, C.C. (1986). Toward a comprehensive model of change. In W. Miller \& N. Heather (Eds.), Treating addictive behaviors (pp. 3-27). New York: Plenum Press.

Prochaska, J.O., DiClemente, C.C., \& Norcross, J.C. (1992). In search of how people change: Applications to addictive behaviors. American Psychologist, 9, 1102-1114.

Prochaska, J.O., DiClemente, C.C., Velicer, W.F., \& Rossi, J.S. (1993). Standardized, individual self-help programs for smoking cessation. Health Psychology. 
Prochaska, J.O., DiClemente, C.C., Velicer, W.F., Ginpil, S., \& Norcross, J.C. (1985). Predicting change in smoking status for self-changers. Addictive Behaviors, 10, 395406 .

Prochaska, J.O., Norcross, J.C., Fowler, J.L., Follick, M.J., \& Abrams, D.B. (1992). Attendance and outcome in a worksite weight control program: Processes and stages of change as process and predictor variables. Addictive Behaviors, 17, 35-45.

Prochaska, J.O., Redding, C.A., Harlow, L.L., Rossi, J.S., \& Velicer, W.F. (in press). The Transtheoretical model of change and HIV prevention. Health Education Quarterly.

Prochaska, J.O., Velicer, W.F., DiClemente, C.C., Fava, J.I. (1988). Measuring processes of change: Applications to the cessation of smoking. Journal of Consulting and Clinical Psychology, 56, 520-528.

Prochaska, J.O., Velicer, W.F., Guadagnoli, E., \& Rossi, J.S., DiClemente, C.C. (1991). Patterns of change: Dynamic typology applied to smoking cessation. Multivariate Behavioral Research, 26, 83-107. 
Prochaska, J.O., Velicer, W.F., Rossi, J.S., Goldstein, M.G., Marcus, B.H., Rakowski, W., Fiore, C., Harlow, L.L. Redding, C.A., Rosenbloom, D., Rossi, S. (in press). Stages of change and decisional balance for twelve problem behaviors. Health Psychology

Rakowski, W., Dube, C., Marcus, B.H., Prochaska, J.O., Velicer, W.F., \& Abrams, D.B. (1992). Assessing elements of a women's decisions about mammography. Health Psychology, 11, 111-118.

Rogers; E.M. (1983). Diffusion of innovations (3rd ed.). New York: Free Press.

Rosenbloom, D. (1991). A transtheoretical analysis of the Stages and processes of change in cocaine users. Unpublished doctoral dissertation, Kingston, R.I.

Rossi, J.S. (1989a). Exploring behavioral approaches to UV risk reduction. In A. Moshell \& L.W. Blankenbaker (Eds.), Sunlight, ultraviolet radiation, and the skin (pp. 9193). Bethesda, MD: National Institutes of Health. 
Rossi, J.S. (1989b). The hazards of sunlight: A report on the Consensus Development Conference on Sunlight, Ultraviolet Radiation, and the Skin. The Health Psychologist, 11( $\underline{3})$, $4-6$.

Rossi, J.S. (1990, August). Radon and ultraviolet light exposure: Emerging cancer risk factors. In J.O. Prochaska (Chair), The stages of change: Extensions to new areas of Behavior change. Symposium presented at the 98th annual conference of the American Psychological Association, Boston, MA.

Rossi, J.S. (1992, August). Common Processes of Change Across Nine Problem Behaviors. Paper presented at the 100th annual convention of the American Psychological Association, Washington, D.C.

Rossi, J.S., \& Blais, L.M. (1991, March). The pros and cons of using sunscreens. Paper presented at the 12 th annual meeting of the Society of Behavioral Medicine, Washington, DC. 
Rossi, S.R., Rossi, J.S., \& Prochaska, J.O. (1990, August). A stage model for reducing dietary fat. In J.O. Prochaska (Chair), The stages of change: Extensions to new areas of behavior change. Symposium presented at the 98 th annual conference of the American Psychological Association, Boston, MA.

Rossi, J.S., Velicer, W.F., Prochaska, J.O., \& DiClemente, C.C. (1989, April). Integrating relapse situations and self-efficacy: An hierarchical structural model. Paper presented at the 10th annual meeting of the society for Behavioral Medicine, San Francisco, CA.

Schmid, T.L., Jeffrey, R.W., \& Hellerstedt, W.L. (1989). Direct mail recruitment to home-based smoking and weight control programs: A comparison of strengths. Preventive Medicine, 18, 503-517.

Shiffman, S. (1982). Relapse following smoking cessation: A situational analysis. Journal of Consulting and Clinical Psychology, 50, 71-86.

Shiffman, S. (1986). A cluster-analytic classification of smoking relapse episodes. Addictive Behaviors, 11, $295-$ 307 . 
Skinner, C.S., Strecher, V.J., \& Hospers, H.J. (in press). Physician recommendations for mammography: Do tailored messages make a difference? American Journal of Public Health.

Snow, M.G., Prochaska, J.O., \& Rossi, J.S. (1991, March). Processes of change amongst self-changers and $A A$ attendees: Analysis of long-term abstinence from alcohol problems. Paper presented at the 12th Annual Meeting of the Society of Behavioral Medicine, Washington, DC.

Stern, R.A., Prochaska, J.O., Velicer, W.F., \& Elder, J.P. (1987). Stages of adolescent cigarette smoking acquisition: Measurement and sample profiles. Addictive Behaviors, 12, $319-329$.

Tucker, L.R., \& Lewis, C. (1973). A reliability coefficient for maximum likelihood factor analysis. Psychometrika, 38, $1-10$.

US Department of Health and Human Services. (1990). Reducing the health consequences of smoking: 25 years of progress. A report of the Surgeon General. Rockville, MD: Public Health Service, Centers for Disease Control, Center for Chronic Disease Prevention and Health Promotion, Office 
on Smoking and Health.

US Department of Health and Human Services. (1986). Healthy People 2000: National Health Promotion and Disease Prevention Objectives. Washington, DC: US Government Printing Office.

USDHEW (1975). Adult use of tobacco. US Government Printing Office, Washington, DC. Publication No. 21-74-520.

USDHEW (1979). A report of the Surgeon General. Public Health Services, Washington, DC. Publication No. 79-50066.

Velicer, W.F., Diclemente, C.C., Prochaska, J.O., \& Brandenburg, N. (1985). Decisional balance measure for assessing and predicting smoking status. Journal of Personality and Social Psychology, 48, 1279-1289.

Velicer, W.F., Diclemente, C.C., Rossi, J.S., \& Prochaska, J.O. (1990). Relapse situations and self-efficacy: An integrative model. Addictive Behaviors, 15, 271-283.

Velicer, W.F., Fava, J.L., Abrams, D.B., Goldstein, M.G., Niaura, R.S., \& Rakowski, W. (1993). Design for a small state. Preventive Medicine, manuscript submitted for 
publication.

Velicer, W.F., Hughes, S.L., Fava, J.L., Prochaska, J.O., \& Diclemente, C.C. (1992). An empirical typology of subjects within stages of change. Manuscript under review.

Velicer, W.F., Prochaska, J.O., Bellis, J.M., DiClemente, C.C., Rossi, J.S., Fava, J.L. \& Steiger, J.H. (in press). An expert system intervention for smoking cessation. Addictive Behaviors.

Velicer, W.F., Rossi, J.S., Prochaska, J.O., \& DiClemente, C.C. (1992). A criterion measurement model for addictive behaviors. Submitted for publication.

Velicer, W.F., Rossi, J.S., Prochaska, J.O., \& Snow, M.G. (1992). Assessing outcome in smoking cessation studies. Psychological Bulletin, 111, 23-41.

Weinstein, N.D. (1988). The precaution adoption process. Health Psychology, $7,355-386$.

Wilcox, N., Prochaska, J.O., Velicer, W.F., \& DiClemente, C.C. (1985). Client characteristics as predictors of self- 
change in smoking cessation. Addictive Behaviors, 40 , 407-412. 